Henrique de Mello de Assunção

\title{
Uma Análise da Eficiência de Custos Operacionais das Companhias de Distribuição Elétrica: uma Aplicação DEA e MDEA em Dois
}

Estágios 
Henrique de Mello de Assunção

\title{
Uma Análise da Eficiência de Custos Operacionais das Companhias de Distribuição Elétrica: uma Aplicação DEA e MDEA em Dois Estágios
}

\author{
Dissertação de Mestrado apresentada ao Pro- \\ grama de Pós-Graduação em Economia- da \\ Faculdade de Economia, Contabilidade e \\ Administração da Universidade de Brasília, \\ como requisito parcial para obtenção do tí- \\ tulo de Mestre em Economia.
}

\author{
Universidade de Brasília - UnB \\ Faculdade de Economia, Administração e Contabilidade \\ Programa de Pós-Graduação
}

Orientador: Professor Moisés de Andrade Resende Filho

Brasil

2018 
Henrique de Mello de Assunção

Uma Análise da Eficiência de Custos Operacionais das Companhias de Distribuição Elétrica: uma Aplicação DEA e MDEA em Dois Estágios/ Henrique de Mello de Assunção. - Brasil, 2018-

47 p. : il. (algumas color.) ; $30 \mathrm{~cm}$.

Orientador: Professor Moisés de Andrade Resende Filho

Dissertação (Mestrado) - Universidade de Brasília - UnB

Faculdade de Economia, Administração e Contabilidade

Programa de Pós-Graduação, 2018.

1. DEA. 2. MDEA. I. Moisés de Andrade Resende Filho. II. Universidade de Brasília. III. Faculdade de Economia, Administração e Contabilidade. IV. Mestre 


\section{Uma Análise da Eficiência de Custos Operacionais das Companhias de Distribuição Elétrica: uma Aplicação DEA e MDEA em Dois Estágios}

Dissertação de Mestrado apresentada ao Programa de Pós-Graduação em Economia- da Faculdade de Economia, Contabilidade e Administração da Universidade de Brasília, como requisito parcial para obtenção do título de Mestre em Economia.

Trabalho avaliado. Brasil, 18 de Janeiro de 2018:

Professor Moisés de Andrade Resende Filho

Universidade de Brasília - Faculdade de Economia, Contabilidade e Administração

Professor Vander Mendes Lucas Universidade de Brasília - Faculdade de Economia, Contabilidade e Administração

Professor Sérgio Ricardo de Brito Gadelha

Secretária do Tesouro Nacional

Brasil 
Este trabalho é dedicado aos meus avôs. 


\section{Agradecimentos}

Agradeço a Deus por existir.

Gostaria de agradecer o apoio prestado pela CAPES.

Agradeço ao professor Moisés pelo apoio e orientação proporcionados durante a elaboração desta pesquisa.

Agradeço aos meus amigos Ágatha, Renan e Nerissa. Obrigado pela ajuda e pelo tempo dedicado. Sem o seu auxílio este trabalho teria sido bem pior.

Gostaria de agradecer a minha família, Flávio, Lisiane, Matheus e Flávia por todo o auxílio nos momentos mais difíceis. Agradeço especialmente ao meu irmão Matheus, o seu apoio, críticas e sugestões foram de valor inestimável.

Agradeço por fim a minha namorada, Isabelle, sem a qual, sem dúvida, este trabalho não teria sido concluído. 
"Confie no processo." 


\section{Resumo}

O presente trabalho analisa a eficiência das distribuidoras elétricas brasileiras a partir de uma análise em dois estágio com o método DEA e MDEA. Verificou-se que as distribuidoras são em sua maioria ineficientes, operando com diferentes tipos de retornos de escala. Segundo a análise feita, existe a possibilidade de uma economia de quatro bilhões de reais a partir de ganhos de eficiência no setor. A análise MDEA possibilita a diferenciação entre firmas eficientes e lida com o efeito ratchet presente na regulação que utiliza o método DEA. O método MDEA é uma forma de obter informações das firmas, que deveriam ser utilizadas pelo regulador. Por fim, a analise em segundo estágio sugere que as firmas privadas são mais eficientes que as públicas, enquanto as firmas da região Norte são menos eficientes que as do Centro-Oeste. Uma possibilidade para a diferença entre firmas privadas e públicas é a diferença na composição dos gastos. Uma possível razão para a diferença de eficiência da região Norte é limitação de infraestrutura da região.

Palavras-chaves: DEA, MDEA, Análise em dois estágio, Distribuidoras. 


\section{Abstract}

The present work analyzes the efficiency of the Brazilian electricity distributors based on a two-stage analysis using the DEA and MDEA methods. It was found that mostly of the distributors are inefficient, operating with different types of returns of scale. According to the analysis, there is the possibility of saving almost four billion reais from gains in efficiency in the sector. The MDEA analysis allows the differentiation between efficient firms, and also deals with the ratchet effect, present in the regulation that uses the DEA method. The MDEA method is a way of obtaining information from the firms that should be used by the regulator. Finally, the second-stage analysis suggests that private firms are more efficient than public firms while firms in the North are less efficient than those in the Midwest. One possibility for the difference between private and public firms is the difference in the composition of expenditures. One possible reason for the diffence between the distributors in the North region and those in the Midwest is the lack of infrastructure of the North region.

Key-words: DEA, MDEA, Two-stage analyses, Energy Distributors. 


\section{Lista de tabelas}

Tabela 1 - Trabalhos sobre eficiência do setor de distribuição elétrica . . . . . . . 16

Tabela 2 - Parâmetros e tecnologia DEA . . . . . . . . . . . . . 22

Tabela 3 - DEA: Variáveis . . . . . . . . . . . . . . . . 26

Tabela 4 - OPEX: composição . . . . . . . . . . . . . . 27

Tabela 5 - OPEX: composição relativa . . . . . . . . . . . . . 27

Tabela 6 - Estatísticas descritivas: Produtos . . . . . . . . . . . . 28

Tabela 7 - Variáveis Ambientais . . . . . . . . . . . . . . . . 30

Tabela 8 - DEA: Todas as distribuidoras . . . . . . . . . . . . 32

Tabela 9 - Estatísticas descritivas da análise DEA . . . . . . . . . . . . 33

Tabela 10 - Retornos de Escala . . . . . . . . . . . . . . . . . . 34

Tabela 11 - DEA supereficiência . . . . . . . . . . . . . . 36

Tabela 12 - Estatísticas descritivas da análise DEA supereficiência . . . . . . . . 37

Tabela 13 - Regressões sobre escores DEA: MQO e MQO com erros robustos . . . 38

Tabela 14 - Regressões sobre escores DEA: TOBIT . . . . . . . . . . . . . 39 


\section{Sumário}

Lista de tabelas .................... . . 9

1 INTRODUÇÃO $\ldots \ldots \ldots \ldots \ldots \ldots$

2 REVISÃO DE liteRATURA . . . . . . . . . . . . . . . . . 13

2.1 Regulação e Setor Elétrico Brasileiro . . . . . . . . . . . . . 13

2.1.1 Regulação . . . . . . . . . . . . . . . . . 13

2.1.2 Setor Elétrico Brasileiro - SEB . . . . . . . . . . . . . . . . 13

2.2 Resultados encontrados . . . . . . . . . . . . . . 15

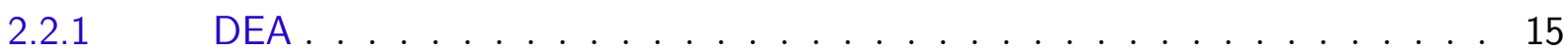

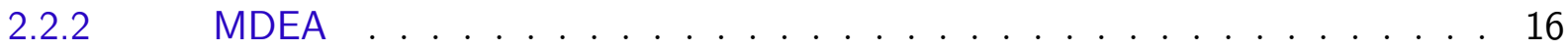

2.2.3 Heterogeneidade e Segundo Estágio . . . . . . . . . . . . . . . . 17

2.2.4 Empresas Públicas vs Privadas . . . . . . . . . . . . . . . . . . . 18

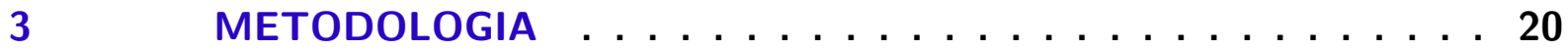

3.1 Análise por Envoltória de Dados em dois estágios . . . . . . . . . . 20

3.1.1 Análise por Envoltória de Dados - DEA . . . . . . . . . . . . 20

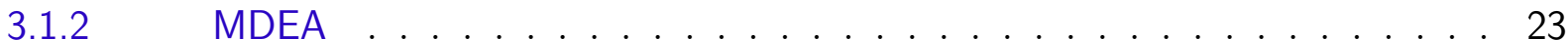

3.1.3 Segundo estágio . . . . . . . . . . . . . . . . . 24

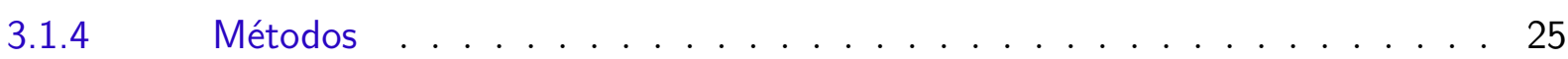

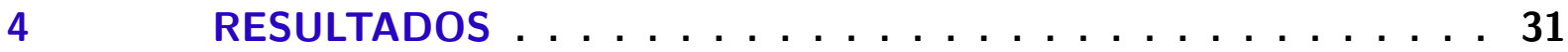

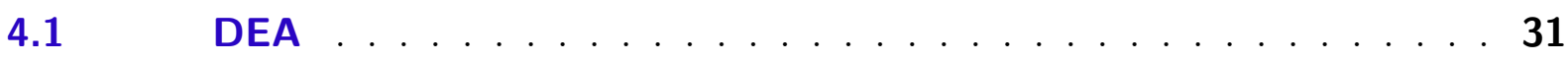

$4.2 \quad$ MDEA: Supereficiência . . . . . . . . . . . . . 35

$4.3 \quad$ Segundo estágio . . . . . . . . . . . . . . . . . . . . 38

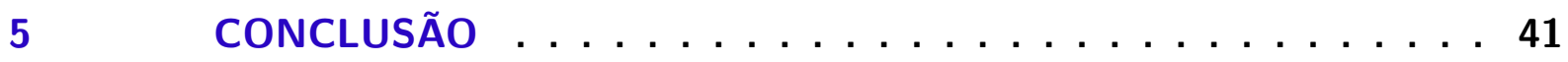

REFERÊNCIAS . . . . . . . . . . . . . . 43 


\section{Introdução}

Vários setores da economia operam com falhas de mercado (BATOR, 1958), sendo o de distribuição elétrica um deles (LOPES et al., 2016). Devido às características de monopólio natural da distribuição de energia elétrica, não é possível que o setor opere como mercado competitivo (LEME et al., 2014). Desta forma, é necessária outra instituição para a escolha de qualidade, preço e quantidade de produto providos pelas firmas do setor.

Diferentes métodos foram usados ao longo da história para lidar com o problema das falhas de mercado no setor de distribuição elétrica (AGRELL et al., 2005) como: regulação por taxa de retorno, nacionalização do setor e competição yardstick. Atualmente, o método usado pela Agência Nacional de Energia Elétrica (ANEEL) para regular as distribuidoras é o de regulação por competição yardstick, no qual a agência reguladora cria uma competição virtual entre as firmas fornecedoras através de suas medidas de eficiência. Para operacionalizar a competição, a ANEEL utiliza a análise envoltória de dados (data envelopment analysis - DEA) para medir a eficiência relativa das distribuidoras. Com base nos resultados obtidos por meio do método DEA, reajusta as tarifas de acordo com o desempenho destas comparadas com as outras firmas do setor (ANEEL, 2015).

O método DEA é um método de análise de eficiência de firmas com múltiplos insumos e produtos. Este método envolve a construção por partes de uma fronteira sobre os dados e o cálculo da eficiência de cada unidade tomadora de decisão (Decision Making Unit - DMU) a partir de sua distância para esta fronteira (COELLI et al., 2005). Além de ser o método usado pela ANEEL (ANEEL, 2015), o DEA é utilizado por outros reguladores do setor elétrico (JAMASB; POLLITT, 2001) para a regulação. Algumas limitações do método são: a incapacidade de diferenciação entre firmas eficientes (ANDERSEN; PETERSEN, 1993) e o efeito ratchet, que é a possibilidade da firma competir consigo mesma (AGRELL et al., 2005).

Essas limitações podem dificultar o uso deste método de análise de eficiência pelo regulador devido ao interesse deste em classificar as firmas e criar incentivos para o contínuo aumento da eficiência delas. No atual modelo, que utiliza o método DEA, as firmas podem vir a competir consigo mesmas, de forma que elas têm um incentivo para não melhorar. Um método para lidar com ambos os problemas é a análise envoltória de dados com supereficiência ou análise envoltória de dados modificada (modified form of data envelopment analysis - MDEA). Essa extensão do método DEA permite a diferenciação entre firmas eficientes ao mesmo tempo que impede que a firma compita consigo mesma. Isso ocorre pois a extensão retira a firma do conjunto de empresas referenciais com quais ela será comparada. 
O objetivo geral dessa dissertação é investigar a aplicação do método MDEA em conjunção com o método DEA enquanto forma de aprimorar a descrição e análise da eficiência do setor elétrico de distribuição brasileiro, auxiliar na criação de mecanismos de regulação que sejam eficientes no longo prazo e superar limitações do método DEA original. Não foi encontrado nenhum outro trabalho que utiliza o método MDEA para as distribuidoras brasileiras. Ademais, tem-se por objetivos específicos investigar os condicionantes dos níveis de eficiências das empresas distribuidoras de energia elétrica no Brasil. Desta forma o trabalho busca estimar a eficiência técnica relativa das distribuidoras e os fatores ambientais que afetam sua operação. Para atender esses objetivos foi realizada uma análise das distribuidoras elétricas brasileiras em dois estágios utilizando o método DEA e o método MDEA no primeiro estágio e fazendo regressões sobre os resultados obtidos no segundo estágio.

Testa-se a hipótese de que as distribuidoras de energia elétrica privadas são mais eficientes do que as distribuidoras públicas. Como não foi determinado se a divisão entre os grupos foi aleatório o resultado do teste é meramente descritivo da situação observada, não estabelecendo um nexo causal.

A pesquisa vai ao encontro do já observado na literatura, observando que as distribuidoras privadas são mais eficientes do que as públicas (FERNANDES; RESENDE FILHO, 2017), (BOENTE; LUSTOSA, 2016), (TANNURI-PIANTO et al., 2009) e (JACOB, 2016). Uma possibilidade para explicar essa divergência entre as distribuidoras privadas e as públicas é a diferença observada na composição dos gastos entre os dois grupos. É possível que uma explicação para o valor da dummy da região Norte seja a falta de infraestrutura da região.

A presente dissertação é dividida em cinco seções, sendo a introdução a primeira delas. A segunda seção faz uma revisão da literatura sobre o Setor Elétrico Brasileiro (SEB), a qual abrange o método DEA e o método MDEA, regressões e resultados destes métodos aplicados ao SEB e outros países. A terceira seção discorre sobre os métodos e instrumentos utilizados para a análise das distribuidoras elétricas brasileiras. A quarta seção apresenta os resultados da análise. A quinta seção conclui o trabalho. 


\section{Revisão de Literatura}

\subsection{Regulação e Setor Elétrico Brasileiro}

\subsubsection{Regulação}

O SEB é composto por quatro segmentos: geração, transmissão, distribuição e comercialização (CONSTANT et al., 2017). Destes dois segmentos operam como monopólio natural: a transmissão e a distribuição de energia elétrica (TOVAR et al., 2011). No caso das distribuidoras devido aos altos custos de manutenção e criação de um estrutura de distribuição de energia elétrica, apenas uma distribuidora opera por região (LEME et al., 2014), não existindo competição local entre distribuidoras.

Dessa forma, distribuidoras de energia elétrica podem cobrar preços em nível de monopólio na falta de regulação. É necessário um arcabouço institucional para que este setor opere de modo eficiente (AGRELL et al., 2005), não gerando um alto custo social. Esse arcabouço precisa obter informações das distribuidoras e transmissoras de energia para poder estabelecer um sistema de preços eficientes.

O principal problema na regulação do setor é a obtenção de informações das firmas pelo regulador, ou seja, diminuir a assimetria de informação que existe entre os agentesas firmas- e o principal- o regulador. Os modelos de regulação do setor elétrico buscam então mitigar a assimetria de informação entre as distribuidoras e o órgão regulador e obter um preço para que os mercados operem de maneira eficiente (LOPES et al., 2016).

Ao longo da história, já foram utilizados diferentes arranjos institucionais com o objetivo de fazer com que o setor opere de forma eficiente, como: nacionalização do setor, regulação por taxa de retorno, competição por yardstick (AGRELL et al., 2005), dentre outros. Os métodos funcionam da seguinte maneira: a nacionalização internalizaria os preços, a regulação por taxa de retorno permitiria que a firma obtivesse uma taxa de retorno de acordo com seus custos e a competição por yardstick, que foi inicialmente proposta por Shleifer (1985), criaria um mercado virtual entre as diferentes firmas, que receberiam de acordo com seu desempenho em relação as outras.

\subsubsection{Setor Elétrico Brasileiro - SEB}

No Brasil, assim como em diferentes países do mundo (JAMASB; POLLITT, 2001)(BOENTE; LUSTOSA, 2016), recorreu-se à integração vertical do setor elétrico com o controle governamental direto sobre ele. Entretanto, o modelo foi sendo substituído no 
final do século XX (JAMASB; POLLITT, 2001). Um dos motivadores das mudanças que ocorreram no Brasil foi a situação financeira crítica pela qual o setor elétrico passou, a qual levou ao processo de reforma que ocorreu na década de 1990 (TOVAR et al., 2011). Uma das razões para a situação crítica era um sistema de subsídios cruzados entre firmas ineficientes e firmas eficientes (TOVAR et al., 2011), o qual reduzia o incentivo das firmas a ganhos de produtividade.

O SEB passou por várias modificações durante a década de 1990 e 2000 devido aos problemas pelos quais passou, tais como a crise financeira do final da década de 1980 e do começo da década de 1990 e o racionamento do começo dos anos 2000.

Com o novo modelo, o Estado passou a regular o setor elétrico ao invés de controlar a produção diretamente. Entre as mudanças que ocorreram no Sistema, podemos citar: privatizações de diversas companhias, desverticalização do sistema com a separação dos segmentos de geração, transmissão e comercialização, criação da ANEEL, alteração do sistema de regulação (TOVAR et al., 2011)(ANDRADE et al., 2014). Os objetivos da nova regulação eram aumentar a eficiência do setor elétrico (SOUZA et al., 2014), remunerar adequadamente as distribuidoras elétricas, manter os preços justos para os consumidores (LOPES et al., 2016) e fazer com que as distribuidoras tivessem incentivo para continuar a melhorar sua produtividade (PESSANHA et al., 2010).

A regulação do setor de distribuição de energia elétrica desde 2003 baseia-se nos ciclos de revisão tarifária (FERNANDES; RESENDE FILHO, 2017), (REZENDE et al., 2014). A tarifa das distribuidoras é revisada a cada ciclo, no qual a ANEEL estabelece uma tarifa máxima. A cada ano, a tarifa é reajustada de acordo com o IGP-M, que é utilizado como medida da inflação, com uma redução pelo fator X. O fator X é calculado a partir de comparações entre as diferentes distribuidoras. Se a distribuidora é eficiente, ela pode alterar sua tarifa pela inflação. Caso não seja, a distribuidora deve alterar sua tarifa pela inflação com um desconto, este desconto é devido a necessidade da distribuidora de alcançar a fronteira de eficiência e repassar os ganhos ao consumidor. A redução do reajuste pelo fator $\mathrm{X}$ tem como objetivo manter o equilíbrio entre receitas e despesas eficientes da firma (BRASIL, 2017). Os consumidores então recebem parte dos ganhos de eficiência da distribuição de energia, que ocorrem por ganho de escala e não pela melhora do gerenciamento da firma (REZENDE et al., 2014).

Nos dois primeiros ciclos de revisão tarifária, 2003-2006 e 2007-2010, a ANEEL utilizou o método de empresa de referência para comparar as diferentes distribuidoras de energia. A partir do terceiro ciclo de revisão tarifária, a ANEEL passou a utilizar as metodologia DEA (REZENDE et al., 2014), e "Corrected Ordinary Least Square"(CMQO) (XAVIER et al., 2015), para analisar as empresas. No quarto ciclo, a ANEEL começou a empregar somente o método DEA. 


\subsection{Resultados encontrados}

\subsubsection{DEA}

O método DEA tem ganhado popularidade na literatura acadêmica nas últimas décadas, tendo o volume de publicações aumentado consideravelmente (SUEYOSHI et al., 2017); (EMROUZNEJAD; YANG, 2017). Diferentes frentes de pesquisa relacionadas ao DEA foram criadas nas últimas décadas (LIU et al., 2016), tanto de caráter teórico quanto prático. O método também tem sido utilizado para a análise e regulação de diferentes setores, inclusive o setor elétrico em diferentes países (XAVIER et al., 2015);(AGRELL et al., 2005);(ANDRADE et al., 2014); (CONSTANT et al., 2017).

O método é utilizado pela ANEEL para a regulação das distribuidoras de energia elétrica brasileiras (ANEEL, 2015). Diferentes estudos brasileiros criticam o método DEA utilizado pela ANEEL e buscam propor melhorias. Rezende et al. (2014) crítica o método usado no terceiro ciclo de revisão e sugere duas mudanças: o uso de avaliação cruzada, para identificar pesos irreais para insumos e produtos, e o uso do método Wald, para agrupar as DMUs em grupos mais homogêneos, melhorando a aplicação do método sobre os grupos. Lopes et al. (2016) faz críticas ao modelo apresentado no quarto ciclo de revisão por utilizar restrições de peso, pela falta de estudo quanto a variáveis ambientais e pela seleção das variáveis.

Andrade et al. (2014) analisam a eficiência das distribuidoras elétricas brasileiras por intermédio do método DEA. Os autores utilizam o método Self Organizing Maps para dividir as DMUs em grupos comparáveis, os autores argumentam que esta técnica seria uma alternativa para lidar com a heterogeneidade das distribuidoras à utilização de regressões no segundo estágio. Os autores também utilizam a técnica de fronteira invertida para conseguir a classificação de todas as DMUs analisadas. Os autores encontram que a ANEEL pode estar subestimando os resultados de eficiência de áreas com características ambientais desfavoráveis.

Constant et al. (2017) utilizam o método DEA para analisar as distribuidoras de energia elétrica brasileira. Assim como em Andrade et al. (2014) as DMUs são agrupadas em grupos semelhantes antes da análise DEA, que é feita dentro destes grupos. Os autores utilizam o índice IV, baseado na distância das DMUs até a fronteira. A divisão em grupos eliminaria a necessidade da etapa de regressão, usada para ajustar os escores de eficiência DEA, e o índice IV permitiria classificar as DMUs.

Tschaffon e Meza (2014) consideram que as distribuidoras de energia elétrica brasileira produzem uma quantidade de produtos indesejados, como insatisfação do consumidor e interrupções no abastecimento. Os autores analisam a eficiência das distribuidoras con- 
siderando estes produtos, utilizando o método DEA com diferentes especificações. Devido ao alto número de variáveis consideradas várias distribuidoras foram consideradas eficientes, para aumentar o poder de discrição do método este foi complementado com a análise por fronteira invertida.

A tabela 1 mostra uma amostra dos trabalhos analisados nesta pesquisa e as variáveis usadas nestes trabalhos.

Tabela 1 - Trabalhos sobre eficiência do setor de distribuição elétrica

\begin{tabular}{|c|c|c|c|}
\hline Variável & Metodologia & Insumo & Produto \\
\hline $\begin{array}{l}\text { Rezende et al. } \\
(2014)\end{array}$ & DEA & OPEX & $\begin{array}{l}\text { Extensão da rede, Mercado, Número de unidades } \\
\text { consumidoras }\end{array}$ \\
\hline $\begin{array}{l}\text { Pérez-Reyes e } \\
\text { Tovar }(2009)\end{array}$ & DEA & $\begin{array}{l}\text { Vendas de energia e } \\
\text { número de } \\
\text { consumidores }\end{array}$ & $\begin{array}{l}\text { Número de trabalhadores, Perdas e Estações de } \\
\text { Conversão, Tamanho da Rede }\end{array}$ \\
\hline Chen (2002) & DEA & $\begin{array}{l}\text { Custos Gerais, } \\
\text { Tamanho da Rede, } \\
\text { Capacidade Total dos } \\
\text { Transformadores }\end{array}$ & $\begin{array}{l}\text { Consumidores e Oferta de Energia por Nível de } \\
\text { Voltagem, Oferta de Energia de Alta Voltagem, Demanda } \\
\text { Máxima, Receita por Energia Distribuída, Mão de Obra } \\
\text { da Área de Concessão }\end{array}$ \\
\hline $\begin{array}{l}\text { Arcos-Vargas et } \\
\text { al. (2017) }\end{array}$ & DEA & Remuneração, Ativos & $\begin{array}{l}\text { Energia Distribuída, Unidades Consumidoras, Energia } \\
\text { não Distribuída }\end{array}$ \\
\hline $\begin{array}{l}\text { (TOVAR et al., } \\
2011)\end{array}$ & SFA & $\begin{array}{l}\text { Extensão da rede, } \\
\text { Número de } \\
\text { empregados, Perdas }\end{array}$ & Vendas, Número de Consumidores \\
\hline $\begin{array}{l}\text { Tannuri-Pianto } \\
\text { et al. (2009) }\end{array}$ & SFA & OPEX Médio & $\begin{array}{l}\text { Volume de Energia Suprida, Salário Médio, Custo da } \\
\text { Energia Comprada, Densidade de Consumidores, } \\
\text { Privatização, Participação no Mercado, Mista }\end{array}$ \\
\hline $\begin{array}{l}\text { Fernandes e } \\
\text { Resende Filho } \\
\text { (2017) }\end{array}$ & DEA & OPEX ajustado & $\begin{array}{l}\text { Energia Distribuída, unidades consumidoras, Número de } \\
\text { consumidores }\end{array}$ \\
\hline $\begin{array}{l}\text { Andrade et al. } \\
(2014)\end{array}$ & DEA & OPEX & Rede, Número de Consumidores e Mercado Composto \\
\hline $\begin{array}{l}\text { Constant et al. } \\
(2017)\end{array}$ & DEA & OPEX & Rede, Número de Consumidores e Mercado Atendido \\
\hline $\begin{array}{l}\text { Leme et al. } \\
(2014)\end{array}$ & DEA & OPEX & Rede, Número de Consumidores e Energia Distribuída \\
\hline $\begin{array}{l}\text { Khodabakhshi } \\
(2010)\end{array}$ & MDEA & $\begin{array}{l}\text { Rede, Capacidade dos } \\
\text { Transformadores e } \\
\text { Empregados }\end{array}$ & Unidades Atendidas e Área Servida \\
\hline
\end{tabular}

Fonte: Elaboração Própria.

\subsubsection{MDEA}

Devido ao fato de o método MDEA manter os escores das firmas ineficientes e alterar apenas os escores das firmas consideradas eficientes no modelo original, os resultados de eficiências do DEA e do MDEA possuem alta correlação. Essa elevada convergência é evidenciada por Espitia-Escuer e García-Cebrián (2014), que comparam os resultados de 
eficiência de três métodos de análise de eficiência: DEA, MDEA e SFA e encontram a alta correspondência mencionada.

Banker e Chang (2006) e Banker et al. (2017) analisam o método de supereficiência a partir de simulações computacionais. Ambos artigos argumentam que o método de supereficiência não é apropriado para a classificação das DMUs eficientes, mas é útil para a identificação de valores discrepantes. O método de supereficiência seria útil para se trabalhar com bases de dados que apresentam ruídos, retirando DMUs cujo escore de eficiência passasse de um certo limite pré-estabelecido.

Khodabakhshi (2010) utiliza supereficiência robusta para classificar as distribuidoras de energia elétrica iraniana. A diferença deste método para o método clássico de supereficiência é que os autores consideraram que os dados apresentavam erros em forma elipsoide e consideraram estes erros no modelo. A partir deste método, os autores classificaram todas as distribuidoras de energia elétrica iranianas. Li e Lin (2015) usam o método DEA com supereficiência para classificação das diferentes províncias chinesas quanto à intensidade do uso de energia elétrica. Os autores observam que a eficiência das províncias varia de acordo com a região em que as províncias se encontram. Lovell et al. (1994) aplicam o método DEA com supereficiência para obtenção de escores de eficiência não limitados superiormente. Estes escores são usados para a análise em segundo estágio com MQO.

\subsubsection{Heterogeneidade e Segundo Estágio}

O método DEA deve ser aplicado a firmas semelhantes (CHARNES et al., 1978), (SOUZA et al., 2010). Desta forma para que a utilização do método sobre o conjunto de distribuidoras elétricas é necessário que estas sejam semelhantes. Como estas firmas usam os mesmos insumos para produzir os mesmos produtos é razoável considerar que elas

sejam semelhantes. É possível, entretanto, que as firmas estejam em condições ambientais tão diferentes que seja necessário considerar estas condições na análise da eficiência das firmas.

As distribuidoras brasileiras encontram-se em diferentes condições ambientais (BOENTE; LUSTOSA, 2016). Diferentes técnicas são usadas para lidar com a heterogeneidade das distribuidoras de energia elétrica brasileiras. Lopes et al. (2016) argumenta que, devido às diferenças de características ambientais das distribuidoras brasileiras, é necessário que haja algum método -como análise em segundo estágio- que contabilize as diferenças ambientais entre as DMUs.

Fernandes e Resende Filho (2017) e ANEEL (2015) utilizam índices salariais para corrigir a variável custos operacionais, que é usada como único insumo. O uso deste índice busca corrigir diferenças nos mercados de trabalho que as diferentes firmas encontram. 
Algumas firmas seriam penalizadas por terem maiores custos, sendo que estes custos viriam do fator exógeno delas encontrarem preços maiores no mercado de trabalho no qual estão inseridas.

Rezende et al. (2014) e Souza et al. (2014) utilizam métodos para classificar as distribuidoras brasileiras em diferentes grupos. O benefício desta divisão seria a comparação entre firmas mais homogêneas, enquanto haveria uma prejuízo pela redução da base de dados analisada.

Fernandes e Resende Filho (2017) utilizam regressões para verificar o impacto de variáveis ambientais nos resultados de eficiência do método DEA. Os autores encontram que distribuidoras privadas e distribuidoras grandes são mais eficientes. Notam também que perdas não técnicas, densidade de consumidores, densidade de rede, descargas e vegetação são insignificantes em seu impacto na eficiência das firmas. Os autores sugerem adicionar a variável área de atuação das distribuidoras.

Çelen (2013) faz uma análise em dois estágios das distribuidoras elétricas da Turquia. O autor observou que o controle privado das firmas, porcentagem de perdas ou roubos e densidade dos consumidores têm impacto positivo na eficiência. Por outro lado, a porcentagem de venda de energia para consumidores residenciais tem impacto negativo, mas não estatisticamente significante. A dummy usada para observar se houve fusão de distribuidoras tem impacto insignificante. Os resultados permitem analisar o impacto das variáveis, assim como sugerir melhoras para a especificação do modelo.

\subsubsection{Empresas Públicas vs Privadas}

No setor de energia elétrica brasileiro, operam companhias tanto públicas quanto privadas (ABRADEE, 2017). Estudos de eficiência das distribuidoras de energia elétrica, principalmente no Brasil, buscam observar se existe diferença de eficiência a depender das companhias serem públicas ou privadas. Na literatura, encontram-se evidências de que o tipo de propriedade da firma pode alterar a sua eficiência (LOVELL, 2016). Outra razão para o interesse no impacto do tipo de propriedade das distribuidoras são os debates sobre as privatizações que ocorreram e ainda ocorrem na sociedade brasileira.

Em países desenvolvidos, não parece haver diferença entre empresas públicas e privadas, enquanto, em países da América Latina, é observado que empresas privadas operam com maior eficiência (PÉREZ-REYES; TOVAR, 2009). No que diz repeito ao Brasil, a maioria dos estudos analisados observa que as distribuidoras privadas são mais eficientes que as distribuidoras públicas, embora existam divergências. Xavier et al. (2015) não encontram diferença significativa entre as distribuidoras de energia elétrica públicas e privadas. As análises de Fernandes e Resende Filho (2017), Boente e Lustosa (2016), Tannuri-Pianto et al. (2009) e Jacob (2016) encontram evidências de que as distribuidoras 
de energia elétrica privadas sejam mais eficientes em diferentes períodos analisados.

Pérez-Reyes e Tovar (2009) analisaram a eficiência de distribuidoras elétricas peruanas. No Peru, houve a privatização de um conjunto de distribuidoras. Algumas destas foram posteriormente nacionalizadas por não cumprirem os contratos estabelecidos. Os autores não encontraram diferença entre as distribuidoras de energia elétrica públicas ou privadas. Entretanto, observaram uma diferença significativa entre as empresas que passaram por privatização em algum momento e aquelas que nunca tinham sido privatizadas.

O presente trabalho contribui para a literatura ao utilizar o método MDEA para as distribuidoras elétricas brasileiras. Não foi observado nenhum outro trabalho que utilizasse este método para o setor de distribuição elétrica brasileira. Além deste aspecto o trabalho expande analisa os fatores ambientais que afetam as distribuidoras brasileiras. 


\section{Metodologia}

\subsection{Análise por Envoltória de Dados em dois estágios}

\subsubsection{Análise por Envoltória de Dados - DEA}

O DEA é um método para análise de eficiência das chamadas Unidades Tomadoras de Decisão (Decision Making Units - DMU) (SOUZA et al., 2014). O modelo foi inicialmente proposto por Charnes et al. (1978) para análise da eficiência de diferentes agentes, considerando apenas retornos constantes de escala (CRS). Banker et al. (1984) alteraram o método de modo que este passou a considerar retornos variáveis de escala (VRS). Diferentes extensões do método foram feitas ao longo do tempo (COOK; SEIFORD, 2009);(LIU et al., 2016);(BOGETOFT; OTTO, 2010). Estas alterações permitem usos diversos do método e visam responder as críticas levantadas ao longo do tempo.

O método DEA utiliza programação linear para estimar a fronteira de possibilidade de produção (COELLI et al., 2005). O DEA baseia-se no princípio de mínima extrapolação (BOGETOFT; OTTO, 2010). A partir de dados observados de insumos e produtos das DMUs e algumas hipóteses sobre a tecnologia, constrói-se o menor conjunto possível de vetores insumo-produto que satisfaça as hipóteses e contenha todos os pontos de insumoproduto observados nos dados. O conjunto resultante é a menor extrapolação que podemos fazer sobre a fronteira de possibilidade de produção que as firmas enfrentam a partir dos dados e das hipóteses usadas. Normalmente, consideram-se as seguintes hipóteses sobre a tecnologia: convexidade, livre descarte, além de algum tipo de retorno de escala (retornos de escala constantes, não crescentes, não decrescentes ou variáveis) (BOGETOFT; OTTO, 2010).

A partir da fronteira do conjunto estimado e dos dados das DMUs, calcula-se um escore de eficiência para estas (BOGETOFT; OTTO, 2010), (COELLI et al., 2005). Os escores são de eficiência relativa, pois não é observada a função de produção real, apenas uma estimativa dela (ANDERSEN; PETERSEN, 1993).

Dependendo da orientação do modelo, há diferentes interpretações para os escores de eficiência (BOGETOFT; OTTO, 2010), mas, de modo geral, estes representam o quão eficiente em transformar insumos em produtos a DMU em questão é em relação as outras DMUs. As duas orientações mais comuns usadas no método DEA são a orientação para insumo e a orientação para produto. Na orientação para insumo, minimiza-se o insumo, não reduzindo o nível de produto da DMU (CHARNES et al., 2013). Na orientação para o produto, maximiza-se o este, não excedendo os níveis de insumos da DMU (CHARNES 
et al., 2013).

Considerando que temos $N$ insumos, $M$ produtos e $I$ firmas. A $N \times I$ matriz de insumos $X$ é a matriz que representa os insumos de todas as firmas e a matriz $M \times I$ de produtos $Y$ é a matriz que representa o produto de todas as firmas (COELLI et al., 2005). Seja $x_{i}$ o vetor de $N$ insumos usados pela firma $i$ e $y_{i}$ o vetor de $M$ produtos produzidos pela firma $i$. A forma envelope do modelo DEA, com retornos constantes de escala e orientação para insumo, consiste no problema de programação linear apresentado em (3.1) de Coelli et al. (2005). Essa apresentação é semelhante ao método original apresentado por Charnes et al. (1978).

$$
\begin{array}{lll}
\underset{\theta, \lambda}{\operatorname{minimizar}} & & \\
\text { sujeito a } & -y_{i}+Y \lambda & \geq 0 \\
& \theta x_{i}-X \lambda & \geq 0 \\
& \lambda & \geq 0
\end{array}
$$

Onde $\lambda$ é um vetor de tamanho $I$ de pesos. Caso $\lambda_{j}>0$, a firma $j$ é utilizada para a construção da firma virtual com a qual a firma $i$ sera comparada. $\theta$ é o valor de eficiência da i-ésima DMU. Sendo $0 \leq \theta \leq 1$, se $\theta=1$ a DMU é considerada eficiente. Para obter-se o escore de eficiência de todas as DMUs resolve-se este problema para cada DMU $i=1,2, \ldots, I$.

Uma interpretação para o modelo descrito acima é que se toma a DMU $i$ e então contrai-se radialmente o vetor de insumos $x_{i}$ o máximo possível com a restrição da mesma continuar no conjunto de possibilidades de produção estimado pelo método DEA (COELLI et al., 2005). O escore de eficiência das DMU será inversamente proporcional à distância do seu vetor de insumos-produtos para a fronteira de eficiência estimada (LIU et al., 2016).

Os retornos de escala do método DEA podem ser alterados por modificações nas restrições do problema de programação linear, em particular alterando restrições para o vetor $\lambda$ de pesos. Seja $e$ um vetor de uns e considerando o problema de programação linear apresentado em (3.1) para que o modelo adote retornos variáveis de escala adiciona-se a restrição de convexidade $e^{T} \lambda_{j}=1$ (BANKER et al., 1984) (COELLI et al., 2005). Outros retornos de escala podem ser considerados como crescentes e decrescentes. Com a adição da restrição $e^{T} \lambda_{j} \leq 1$ ao modelo (3.1), o método considera que a tecnologia apresenta retornos não crescentes de escala. Com a adição da restrição $e^{T} \lambda_{j} \geq 1$ ao modelo (3.1), o método passa a considerar retornos não decrescentes de escala. Os retornos de escala e suas respectivas restrições podem ser observados na tabela 2.

O escore de eficiência obtido a partir do método DEA com retornos constantes de escala pode ser decomposto em duas partes: eficiência técnica pura e eficiência de escala. 
Tabela 2 - Parâmetros e tecnologia DEA

\begin{tabular}{ll}
\hline Modelo & Parâmetros de retorno de escala \\
\hline Retornos Variáveis de Escala & $e^{T} \lambda=1$ \\
Retornos Decrescentes de Escala & $e^{T} \lambda \leq 1$ \\
Retornos Crescentes de Escala & $e^{T} \lambda \geq 1$ \\
Retornos Constantes de Escala & $\lambda_{j} \geq 0 ; j=1, \ldots, I$ \\
\hline
\end{tabular}

Fonte: Elaboração Própria a partir de Bogetoft e Otto (2010)

A eficiência técnica pura é a eficiência das DMUs em empregar os melhores métodos, considerando retornos variáveis de escala (obtida através do método DEA VRS), e a eficiência de escala, que é a capacidade da firma operar em um nível que a média do conjunto de produto por conjunto de insumo é máxima (BOGETOFT; OTTO, 2010).

O escore de eficiência de escala pode ser calculado através da razão entre o escore de eficiência obtido pelo método DEA com retornos constantes de escala e o escore de eficiência obtido através do método DEA com retornos variáveis de escala (BOGETOFT; OTTO, 2010);(FERNANDES; RESENDE FILHO, 2017). O escore de eficiência de escala diz o quão distante a firma está da escala ótima, mas não informa se a firma opera com retornos crescentes ou decrescentes de escala. Para obter essas informações, se compara os escores de eficiência das DMUS obtidas no método DEA com retornos variáveis, com os escores de eficiência obtidos com retornos constantes e retornos não decrescentes de escala. Seja $\theta_{C R S}$ o escore de eficiência com retornos constantes de escala, $\theta_{V R S}$ o escore de eficiência com retornos variáveis de escala e $\theta_{N D R S}$ o escore de eficiência com retornos não decrescentes. Se $\theta_{C R S}=\theta_{V R S}$, então a DMU está operando em escala ótima. Se $\theta_{C R S} \neq$ $\theta_{V R S}$, então a DMU não está operando em escala ótima. Nesse caso se $\theta_{V R S}=\theta_{N D R S}$, então a DMU está operando com retornos crescentes de escala caso contrário com retornos decrescentes.

Uma das vantagens do método DEA é que não é necessário qualquer informação sobre a relação funcional de insumos e produtos ou qualquer informação sobre o preço dos insumos e produtos (LI; LIN, 2015). Esta flexibilidade do método permite analisar situações econômicas variadas (EMROUZNEJAD; YANG, 2017).

Existem limitações e dificuldades no uso do método DEA. O método analisa a eficiência relativa (ANDERSEN; PETERSEN, 1993), não sendo possível observar o verdadeiro conjunto de possibilidades de produção, apenas o menor conjunto possível que se pode estimar a partir dos dados. Outra limitação do método DEA é que não é possível classificar as firmas consideradas eficientes (ANDERSEN; PETERSEN, 1993).

O DEA trabalha com a suposição de que não há ruído nos dados. Segundo Bogetoft e Otto (2010) caso existam ruídos os resultados não são válidos. Isto ocorre porque, nesse caso, se comparam DMUs que tiveram "sorte"com DMUs que tiveram "azar", de modo que 
o escore de eficiência não representa a eficiência relativa das firmas, mas uma composição da eficiência relativa com a distribuição de erros nos dados. Outros autores discordam da incapacidade do método DEA de lidar com ruídos nos dados. Banker e Natarajan (2008) argumentam que o método DEA é robusto até certo nível de ruído, não sendo correto classifica-lo como método determinístico.

\subsubsection{MDEA}

O modelo DEA modificado para classificar as firmas eficientes foi proposto por Andersen e Petersen (1993). No método MDEA, a DMU é retirada do conjunto de dados com os quais será comparada. Esta modificação permite que as DMUs atinjam escores de eficiência superiores a um, na orientação para insumo, ou inferiores a um, na orientação para produto (LOVELL et al., 1994). As firmas com escores de eficiência maiores que um, na orientação para insumo, e inferiores a um, na orientação para produto, são consideradas supereficientes. Com esta mudança, é possível classificar as firmas consideradas eficientes no método DEA original (LOVELL; ROUSE, 2003).

Considere que temos $N$ insumos, $M$ produtos e $I$ firmas. A $N \times(I-1)$ matriz de insumos $X$ que representa os insumos de todas as firmas, exceto a firma $i$ sendo analisada, e a matriz $M \times(I-1)$ de produtos $Y$ é a que representa o produto de todas as firmas, exceto a firma $i$ sob análise. Seja $x_{i}$ o vetor de $N$ insumos usados pela firma $i$ e $y_{i}$ o vetor de $M$ produtos produzidos pela firma $i$. O método MDEA pode ser descrito pelo conjunto de equações (3.2).

$$
\begin{array}{lll}
\underset{\theta, \lambda}{\operatorname{minimizar}} & & \\
\text { sujeito a } & -y_{i}+Y_{-i} \lambda & \geq 0 \\
& \theta x_{i}-X_{-i} \lambda & \geq 0 \\
\lambda & \geq 0
\end{array}
$$

O método MDEA é semelhante ao método DEA apresentado no problema de programação linear 3.1. No sistema (3.2), consideramos um problema de supereficiência orientado ao insumo com retornos constantes de escala. Com alterações idênticas ao método DEA original, pode-se obter o método MDEA com retornos de escala variáveis, não crescentes e não decrescentes.

As alterações no método fazem com que seja necessário modificar a interpretação do escore de eficiência obtido pelo método MDEA. Os escores de eficiência das firmas ineficientes no modelo original não são alterados e a interpretação destes escores continua igual (ANDERSEN; PETERSEN, 1993). Os escores das firmas supereficientes, na orientação para insumo, representam o quanto se pode aumentar os insumos utilizados pela 
firma, de forma que ela continue eficiente na análise (ANDERSEN; PETERSEN, 1993). De maneira análoga, os escores de eficiência da firma supereficientes no MDEA com orientação para produto representam o quanto se pode diminuir do produto das firmas, mantendo-as entre as firmas eficientes.

A utilização do método MDEA possibilitaria algumas vantagens sobre a utilização do método DEA convencional. A primeira destas é a possibilidade de classificação das firmas eficientes, citada por Andersen e Petersen (1993). Outra vantagem seria a comparação dos resultados DEA com os de outros métodos de estimação de eficiência (ANDERSEN; PETERSEN, 1993). A ANEEL (2015) argumenta que o uso de supereficiência em sua análise permitiria encontrar valores únicos para os pesos dos insumo e produtos. O método MDEA faz com que a firma não seja usada como medida de comparação dela mesma, lidando, assim, com o efeito ratchet (AGRELL et al., 2005). Segundo Bogetoft e Otto (2010) o método MDEA incentivaria a melhora de eficiência de DMUs com escores de eficiência igual a um no DEA original.

Um problema no uso do método DEA com supereficiência é a possibilidade de que algumas firmas não tenham solução factível (CHEN, 2005);(BOGETOFT; OTTO, 2010). Isso ocorre quando não existe solução para o problema de programação linear descrito. $\mathrm{O}$ problema de inviabilidade no método de supereficiência não deve ser ignorado, sendo um problema comum em dados reais (XUE; HARKER, 2002).

\subsubsection{Segundo estágio}

A eficiência das DMUs pode ser influenciada por variáveis fora do controle dessas (ANEEL, 2015), (FERNANDES; RESENDE FILHO, 2017), (BOGETOFT; OTTO, 2010). Estas variáveis que influenciam a função de produção da firma, mas não estão sobre o controle da mesma, são chamadas variáveis ambientais (COELLI et al., 2005). Um exemplo de variável ambiental seria a incidência de raios em uma região. O escore de eficiência neste caso captaria a eficiência técnica e a influência das variáveis ambientais.

Vários procedimentos foram desenvolvidos para incorporar a influência de fatores ambientais na análise de eficiência DEA (MCDONALD, 2009),(SIMAR; WILSON, 2007). Um destes procedimentos é a análise em dois estágios. No primeiro estágio, são calculados os níveis de eficiência das DMUs. Estes níveis de eficiência são então usados como variável dependente de uma regressão no segundo estágio, em que as variáveis explicativas são os fatores ambientais. Desta forma, estima-se o impacto destes fatores nos escores de eficiência.

A análise em dois estágios também pode ser usada para entender as variações de eficiência e para validar o modelo (BOGETOFT; OTTO, 2010). A facilidade de implementação e a maneira de interpretação dos resultados são vantagens significativas para a 
implementação do procedimento de análise em dois estágios (MCDONALD, 2009).

Em uma perspectiva de regulação, a análise em dois estágios é interessante devido à estimação do quanto da variação de eficiência ocorre em razão das ações da própria DMU, e do quanto em razão dos diferentes fatores ambientais considerados (LOVELL et al., 1994). O regulador pode, então, corrigir os sistema de incentivos para considerar as condições específicas de cada DMU do setor regulado.

A regressão no segundo estágio da análise de eficiência DEA é feita normalmente utilizando o método Tobit. O método Tobit é uma técnica de regressão utilizada quando os valores da variável dependentes são censurados em certos valores (HENNINGSEN, 2010). O método Tobit é considerado adequado devido ao limite superior e inferior dos escores de eficiência obtidos através do DEA (JI et al., 2010). Existem críticas ao uso do Tobit. McDonald (2009) argumenta que os dados não são truncados, mas porcentuais ou normalizados, defendendo o uso da estimação por MQO com erros robustos.

Nesta pesquisa foi realizada uma análise DEA em dois estágios. No primeiro estágio foi realizado a análise dos escores de eficiência das DMUs selecionadas utilizando o método DEA e o método MDEA. No segundo estágio foram feitas uma série de regressões sobre os escores obtidos. Esta metodologia é utilizada por uma série de artigos na literatura como Çelen (2013), Fernandes e Resende Filho (2017), Lovell et al. (1994) e foi utilizada pela ANEEL no terceiro ciclo de revisão tarifária (ANEEL, 2011).

\subsubsection{Métodos}

Todas as análises feitas neste artigo foram feitas com o programa $\mathrm{R}$ versão 3.4.2 (R Core Team, 2017). Foi utilizado para análise com o método DEA e MDEA o pacote Benchmarking de Bogetoft e Otto (2015). Para as regressões tobit foi usado o pacote de censReg (HENNINGSEN, 2017). Para a construção de algumas tabelas, foram usados os pacotes stargazer e xtable (HLAVAC, 2015);(DAHL, 2015). Os dados e o código usado estão disponíveis mediante solicitação ${ }^{1}$.

A base de dados utilizada no trabalho compõe-se das informações quanto à distribuição de energia elétrica realizada pelas distribuidoras de energia elétrica brasileiras, utilizada como suporte de ANEEL (2015). Os dados de energia distribuída provém da Abrade (ABRADEE, 2017). A base de dados compreende os anos de 2001 a 2013. Foi escolhido utilizar o ano de 2012 para a análise. Escolheu-se usar o ano de 2012 ao invés de 2013, o último na base dos dados da nota, devido à disponibilidade de dados de energia entregue pelas distribuidoras. Quatro distribuidoras de energia elétrica foram excluídas dos dados pela falta de informações quanto a alguma variável usada, nominalmente: CEA, CERR, Copel e CPEE.

$\overline{1}$ Pelo email henrique.mello1992@gmail.com 
A escolha do método no primeiro estágio consiste na seleção da orientação do método DEA, triagem dos insumos e produtos e das hipóteses usadas, especialmente os retornos de escala.

Segundo Bogetoft e Otto (2010), deve-se escolher a orientação do método DEA de acordo com as variáveis, insumos ou produtos que a DMU têm mais controle. Decidiu-se, então, utilizar o método DEA orientado para o insumo no presente estudo, pois as DMUs teriam mais controle sobre seus insumos do que sobre a demanda, que seria exógena (BOENTE; LUSTOSA, 2016), (BOGETOFT; OTTO, 2010). A orientação para insumo permite uma interpretação do quanto é possível reduzir os insumos atendendo a mesma demanda. A orientação para insumo é utilizada em diversos trabalhos que usam DEA para análise do setor de distribuição elétrica (FERNANDES; RESENDE FILHO, 2017), (ARCOS-VARGAS et al., 2017), bem como pela ANEEL no quarto ciclo de revisão tarifária (ANEEL, 2015).

Foram feitas três análises utilizando o método DEA, cada uma considerando um tipo de retorno de escala diferente. Consideraram-se retornos constantes de escala, retornos não decrescentes de escala e retornos variáveis de escala. A escolha de vários retornos diferentes permite a comparação entre os diferentes resultados, a análise do nível de eficiência de escala e a observação do nível de economia de escala que a firma opera (BOGETOFT; OTTO, 2010). A partir do resultados obtidos foi possível calcular os escores de eficiência de escala das DMUs e, em especial, em que faixa de retorno de escala a DMU opera.

A escolha das variáveis usadas como insumo e produtos no método DEA é crucial, pois os resultados de eficiência dependem diretamente do conjunto de variáveis escolhidas (MARTIĆ; SAVIĆ, 2001);(FERNANDES; RESENDE FILHO, 2017). Diferentes variáveis são usadas para a análise com o método DEA das distribuidoras de energia elétrica. Jamasb e Pollitt (2001) e Arcos-Vargas et al. (2017) fazem uma análise das variáveis usadas por diferentes reguladores e pesquisadores. Observa-se que existe um conjunto de variáveis mais utilizadas, embora não haja consenso na literatura. As variáveis escolhidas neste estudo são apresentadas na tabela 3. Estas variáveis foram selecionadas de acordo com o observado na literatura e pela disponibilidade dos dados.

Tabela 3 - DEA: Variáveis

\begin{tabular}{lll}
\hline Variável & Tipo & Unidade \\
\hline Custos Operacionais (OPEX) & Insumo & Mil Reais \\
Rede Total & Produto & Quilômetro \\
Unidades Consumidoras & Produto & Unidade \\
Energia Distribuída & Produto & Megawatt \\
\hline
\end{tabular}

Fonte: Elaboração Própria.

O insumo escolhido para ser utilizado no método DEA foi o custo operacional 
(OPEX). A utilização do OPEX é comum na literatura (JAMASB; POLLITT, 2001), sendo usado por diferentes autores para análise das distribuidoras brasileiras (SOUZA et al., 2014);(CONSTANT et al., 2017); (LEME et al., 2014). Escolher o OPEX como único insumo faz com que o DEA estime a função custo (BOGETOFT; OTTO, 2010) e o escore de eficiência é a relação da firma com seu OPEX ótimo. o regulador busca informações do custo das firmas para poder escolher a regra de ajuste da tarifa ótima. Esta informação é relevante para o regulador e para o público (ARCOS-VARGAS et al., 2017), pois permite que o regulador escolha um sistema de incentivos que leve a firma a operar em um nível de custos operacionais ótimos.

O OPEX das distribuidoras é composto por gastos com pessoal, materiais, serviços de terceiros, seguros, tributos e outros. Observa-se uma alta variação no OPEX, assim como em qualquer uma de suas partes. Observa-se uma diferença considerável entre os valores máximos e mínimos gastos, sendo o valor máximo maior em mais do que mil vezes do que o mínimo em qualquer tipo de gasto. São apresentadas estatísticas descritivas do OPEX e de seus componentes na tabela 4.

Tabela 4 - OPEX: composição

\begin{tabular}{llllll}
\hline Tipo & Média & Desvio Padrão & Mínimo & Mediana & Máximo \\
\hline OPEX & $267.858,89$ & $368.833,63$ & $1.730,51$ & $154.730,67$ & $2.053 .133,94$ \\
Pessoal & $128.255,99$ & $198.163,18$ & $1.327,88$ & $61.326,13$ & $1.166 .100,15$ \\
Materiais & $9.867,33$ & $13.719,60$ & 53,04 & $4.662,24$ & $67.978,94$ \\
Serviços de Terceiros & $113.290,97$ & $149.782,94$ & 224,58 & $55.558,94$ & $768.099,86$ \\
Seguros & 756,71 & 890,70 & 0,00 & 474,85 & $3.738,39$ \\
Tributos & $3.076,15$ & $6.244,89$ & 2,43 & 875,30 & $32.371,08$ \\
Outros & $12.611,74$ & $21.604,10$ & 10,17 & $3.514,94$ & $111.730,56$ \\
\hline
\end{tabular}

Fonte: Elaboração Própria.

A diferença entre os valores gastos pode ser explicada pela diferença de escala entre distribuidoras. Para analisar a diferença na composição dos gastos, observou-se a diferença na composição relativa dos gastos da OPEX. Os valores da composição relativa da OPEX podem ser observados na tabela 5 .

Tabela 5 - OPEX: composição relativa

\begin{tabular}{lccccc}
\hline Tipo & Média & Desvio Padrão & Mínimo & Mediana & Máximo \\
\hline Pessoal & $52,35 \%$ & $14,32 \%$ & $26,52 \%$ & $50,66 \%$ & $81,64 \%$ \\
Materiais & $4,64 \%$ & $2,03 \%$ & $1,32 \%$ & $4,25 \%$ & $10,91 \%$ \\
Serviços de terceiros & $36,97 \%$ & $13,75 \%$ & $11,45 \%$ & $36,70 \%$ & $66,34 \%$ \\
Seguros & $0,43 \%$ & $0,35 \%$ & $0,00 \%$ & $0,32 \%$ & $1,91 \%$ \\
Tributos & $1,09 \%$ & $1,16 \%$ & $0,03 \%$ & $0,69 \%$ & $7,29 \%$ \\
Outros & $4,53 \%$ & $3,60 \%$ & $0,26 \%$ & $3,52 \%$ & $16,45 \%$ \\
\hline
\end{tabular}

Fonte: Elaboração Própria. 
Os principais gastos na OPEX são de pessoal e serviços de terceiros. Em média, $52 \%$ dos gastos operacionais são com pessoal, enquanto $32 \%$ são com serviços de terceiros. Observa-se que o menor gasto é com seguros, não sendo mais que $2 \%$ dos gastos para qualquer distribuidora. Tributos aparecem como uma parcela pequena dos gastos operacionais não sendo mais que $7 \%$ dos gastos operacionais de qualquer empresa. Pode-se notar que os gastos são realizados principalmente com pessoal, serviços de terceiros, materiais e outros.

Testou-se a hipótese de que as distribuidoras públicas tem média de gasto relativo com pessoal diferente da média de gasto com pessoal das distribuidoras privadas. Para isso realizou-se um teste Welch t, com hipótese nula das médias serem iguais. Obteve-se um estatística t de 3.2261, p-valor de 0.003469. Logo rejeita-se a hipótese nula, sendo preferida a hipótese alternativa de que as médias com gastos relativos de pessoal são diferentes.

Como produto, foram selecionadas três variáveis: tamanho da rede, unidades consumidoras e energia distribuída. Estas variáveis captariam os serviços prestados pela distribuidora e a extensão da necessidade de seu OPEX (FERNANDES; RESENDE FILHO, 2017). As três variáveis em questão são frequentemente usadas na literatura para análise das distribuidoras elétricas (JAMASB; POLLITT, 2001), (ARCOS-VARGAS et al., 2017). Estatísticas descritivas dos produtos utilizados no trabalho podem ser observadas na tabela 6

Tabela 6 - Estatísticas descritivas: Produtos

\begin{tabular}{lclcc}
\hline \hline Variáveis & Média & Desvio Padrão & Min & Max \\
\hline Rede Total & $53.49,730$ & $81.46,160$ & 21,62 & $499.039,80$ \\
Consumo & $4.967,20$ & $7.189,08$ & 13,19 & $37.622,45$ \\
$\mathrm{~N}^{\circ}$ consumidores & 1.144 .230 & 1.600 .650 & 2.743 & 7.483 .776 \\
\hline
\end{tabular}

Fonte: Elaboração Própria.

Assim como observado na variável OPEX, existe uma grande heterogeneidade entre o produto das distribuidoras de energia elétricas brasileiras. O desvio-padrão das variáveis usadas no produto é alto e observa-se que o valor máximo de qualquer produto é mais do que mil vezes maior que o valor mínimo. Esses valores revelam uma grande heterogeneidade de escala entre as distribuidoras do Brasil.

O método MDEA foi aplicado usando as mesmas especificações que o método DEA. Devido ao problema de inviabilidade observado para as distribuidoras ELETROPAULO e CEMIG, foi utilizado o método proposto por Chen (2005) para a correção dos valores das variáveis inviáveis. Este método permite obter escores de eficiência para estas DMUs que representam a possibilidade de economia de insumos, a mesma informação que obtemos 
das outras distribuidoras.

Um problema do uso do método DEA e MDEA para análise das distribuidoras elétricas brasileiras é a diferença observada entre as empresas. Essa diferença é um problema para a comparabilidade das distribuidoras, sendo que a comparabilidade das DMUs quanto a insumos e produtos é uma premissa essencial do método DEA (LOPES et al., 2016). Caso as DMUs não sejam comparáveis, os escores de eficiência perdem o seu sentido, pois se comparam agentes que não compartilham da mesma tecnologia.

Para comparar firmas com diferentes escala são usados diferentes tipos de retorno de escala para a análise. Segundo ANEEL (2015), considerando os retornos crescentes na tecnologia de distribuição, é possível comparar as firmas através do uso da hipótese de retornos não decrescentes de escala no método DEA. Dessa forma, as distribuidoras compartilhariam o mesmo conjunto de possibilidade de produção, sendo que, considerando retornos não decrescentes seria possível comparar todas as distribuidoras.

Para analisar os diferentes ambientes e o impacto desses nos escores de eficiência, foi feita uma análise em segundo estágio dos escores de eficiência. O método escolhido para a análise no segundo estágio é definido pela seleção da forma de regressão, assim como das variáveis a serem usadas na regressão.

Ainda existe debate na literatura quanto ao método correto para se analisar os escores de eficiência no segundo estágio (LIU et al., 2016). Dada a referida falta de consenso, optou-se pela utilização de regressões MQO, MQO com erros robustos e Tobit para a análise em segundo estágio.

O método Tobit foi selecionado por sua presença nas análises em segundo estágio na literatura (ÇELEN, 2013) e por ser considerado adequado para as análises com escores censurados, que seria o caso dos escores obtidos com o método DEA segundo Ji et al. (2010). O método Tobit foi usado apenas na análise dos escores obtidos através do método DEA, uma vez que os escores obtidos pelo método MDEA não são censurados, não há razão para utilização do método sobre estes.

Segundo McDonald (2009) os resultados obtidos através do método Tobit estão aquém dos obtidos por intermédio de MQO. Por esta razão foram utilizados os métodos MQO e MQO com erros robustos para complementar os resultados.

As variáveis foram escolhidas por não estarem diretamente relacionadas as variáveis usadas como insumos e produtos na análise DEA e MDEA no primeiro estágio, assim como pelo seu uso em outros trabalhos que consideram características ambientais como Andrade et al. (2014), Çelen (2013) e Fernandes e Resende Filho (2017). As variáveis "precipitação"e "descargas"foram selecionadas por descreverem as situações climáticas enfrentadas pelas distribuidoras. Já as variáveis "região"e "propriedade"foram selecionadas por descreverem a situação institucional em que a firma se encontra. Por fim, a variável "complexidade"foi 
selecionada por descrever a situação socio-econômica enfrentada pela DMU.

Tabela 7 - Variáveis Ambientais

\begin{tabular}{|c|c|c|}
\hline Variável & Tipo & Unidade \\
\hline Propriedade & Categórica & Se a distribuidora é privada ou pública \\
\hline Região & Categórica & Região do Brasil em que a distribuidora atua \\
\hline Vegetação & Numérica & $\begin{array}{l}\text { Porcentagem de cobertura vegetal natural na área de } \\
\text { cobertura }\end{array}$ \\
\hline Descargas & Numérica & $\begin{array}{l}\text { Média de descargas atmosféricas por quilometro quadrado no } \\
\text { ano }\end{array}$ \\
\hline Precipitação & Numérica & É o nível médio de precipitação na área de concessão \\
\hline Complexidade & Numérica & $\begin{array}{l}\text { Índice calculado pela ANEEL que reflete o grau de } \\
\text { complexidade sócio-econômica da área de concessão da } \\
\text { empresa }\end{array}$ \\
\hline
\end{tabular}

Fonte: Elaboração Própria. 


\section{Resultados}

\subsection{DEA}

Os escores de eficiência das distribuidoras elétricas foram calculados utilizando-se o método DEA. A partir dos resultados obtidos na metodologia DEA foi possível obter a faixa de eficiência em que as DMUs brasileiras operam. Os valores encontrados podem ser observados na tabela 8. Observa-se que dez distribuidoras não atingem a eficiência técnica de $50 \%$ e que sete distribuidoras são eficientes em todas as especificações utilizadas. Observamos a limitação descrita por (ANDERSEN; PETERSEN, 1993), em que o método não é capaz de classificar entre as firmas eficientes.

A tabela 9 apresenta as estatísticas descritivas da análise DEA sobre todas as DMUs analisadas. Foram calculadas a média, o desvio-padrão e o valor mínimo. São apresentados as estatísticas da análise de eficiência em retornos de escala diferentes: retornos constantes (CRS), retornos variáveis (VRS), retornos não decrescentes (IRS) e retornos de escala (Escala).

As distribuidoras apresentam uma eficiência média de 67,77\% com retornos constantes de escala, de 72,64\% para retornos variáveis de escala, de 70,18\% para retornos crescentes de escala e de 93,96\% para retornos de escala. A média de eficiência para as diferentes especificações de retornos de escala permaneceu próxima. Entretanto, a eficiência de escala foi estatisticamente superior aos escores de eficiência observados com o uso das especificações CRS, VRS e IRS (p-valor menor que 0,001 para qualquer comparação, segundo o teste $\mathrm{t}$ de Welch).

Observou-se um alto desvio-padrão para as distribuidoras brasileiras. O desviopadrão de eficiência vai de $11,77 \%$ a $21,71 \%$. Vale ressaltar que o desvio-padrão de $11,77 \%$ é observado na eficiência de escala, enquanto o desvio-padrão de 21,23\% é observado nas análises com retornos constantes, 21,71\% em retornos variáveis de escala e 20,40\% na análise com retornos não decrescentes. As distribuidoras brasileiras têm maior variação em sua eficiência técnica e em sua eficiência técnica pura do que em sua eficiência de escala.

Um caso fora do padrão observado foi o da distribuidora JOAO CESA, que apresenta eficiência de escala de 25,48\%, muito distante das outras distribuidoras analisadas. O baixo valor de eficiência de escala para esta distribuidora foi encontrado também por Fernandes e Resende Filho (2017).

Foram observadas sete ou onze firmas eficientes, dependendo da especificação. Sete 
Tabela 8 - DEA: Todas as distribuidoras

\begin{tabular}{|c|c|c|c|c|c|c|}
\hline Distribuidora & CRS & VRS & IRS & Escala & Classificação & \\
\hline CELTINS & $100,00 \%$ & $100,00 \%$ & $100,00 \%$ & $100,00 \%$ & 1 & Ótimo \\
\hline JAGUARI & $100,00 \%$ & $100,00 \%$ & $100,00 \%$ & $100,00 \%$ & 1 & Ótimo \\
\hline COELBA & $100,00 \%$ & $100,00 \%$ & $100,00 \%$ & $100,00 \%$ & 1 & Ótimo \\
\hline COELCE & $100,00 \%$ & $100,00 \%$ & $100,00 \%$ & $100,00 \%$ & 1 & Ótimo \\
\hline COSERN & $100,00 \%$ & $100,00 \%$ & $100,00 \%$ & $100,00 \%$ & 1 & Ótimo \\
\hline MUXFELDT & $100,00 \%$ & $100,00 \%$ & $100,00 \%$ & $100,00 \%$ & 1 & Ótimo \\
\hline RGE & $100,00 \%$ & $100,00 \%$ & $100,00 \%$ & $100,00 \%$ & 1 & Ótimo \\
\hline PIRATININGA & $98,28 \%$ & $100,00 \%$ & $98,28 \%$ & $98,28 \%$ & 8 & Decrescentes \\
\hline CEMAR & $92,50 \%$ & $92,58 \%$ & $92,58 \%$ & $99,92 \%$ & 9 & Crescentes \\
\hline CELPE & $92,45 \%$ & $94,45 \%$ & $92,45 \%$ & $97,88 \%$ & 10 & Decrescentes \\
\hline BANDEIRANTE & $90,94 \%$ & $93,41 \%$ & $90,94 \%$ & $97,36 \%$ & 11 & Decrescentes \\
\hline AES SUL & $90,41 \%$ & $97,63 \%$ & $90,41 \%$ & $92,60 \%$ & 12 & Decrescentes \\
\hline CPFL PAULISTA & $87,71 \%$ & $100,00 \%$ & $87,71 \%$ & $87,71 \%$ & 13 & Decrescentes \\
\hline ELEKTRO & $85,33 \%$ & $95,09 \%$ & $85,33 \%$ & $89,74 \%$ & 14 & Decrescentes \\
\hline MOCOCA & $84,31 \%$ & $91,19 \%$ & $91,19 \%$ & $92,46 \%$ & 15 & Crescentes \\
\hline ENE. PARAÍBA & $84,18 \%$ & $84,40 \%$ & $84,40 \%$ & $99,74 \%$ & 16 & Crescentes \\
\hline LIGHT & $83,40 \%$ & $96,06 \%$ & $83,40 \%$ & $86,82 \%$ & 17 & Decrescentes \\
\hline CSPE & $82,23 \%$ & $85,85 \%$ & $85,85 \%$ & $95,78 \%$ & 18 & Crescentes \\
\hline CEMAT & $81,14 \%$ & $89,33 \%$ & $81,14 \%$ & $90,82 \%$ & 19 & Decrescentes \\
\hline ELETROPAULO & $80,28 \%$ & $100,00 \%$ & $80,28 \%$ & $80,28 \%$ & 20 & Decrescentes \\
\hline ENE, BORBOREMA & $78,20 \%$ & $78,27 \%$ & $78,27 \%$ & $99,90 \%$ & 21 & Crescentes \\
\hline NOVA PALMA & $77,35 \%$ & $96,21 \%$ & $96,21 \%$ & $80,40 \%$ & 22 & Crescentes \\
\hline ESCELSA & $75,39 \%$ & $75,96 \%$ & $75,39 \%$ & $99,25 \%$ & 23 & Decrescentes \\
\hline CELG & $74,47 \%$ & $82,94 \%$ & $74,47 \%$ & $89,79 \%$ & 24 & Decrescentes \\
\hline AMPLA & $73,33 \%$ & $75,29 \%$ & $73,33 \%$ & $97,39 \%$ & 25 & Decrescentes \\
\hline ENE. MINAS GERAIS & $71,95 \%$ & $72,67 \%$ & $72,67 \%$ & $99,01 \%$ & 26 & Crescentes \\
\hline SANTA CRUZ & $71,72 \%$ & $71,77 \%$ & $71,77 \%$ & $99,93 \%$ & 27 & Crescentes \\
\hline ENERSUL & $71,39 \%$ & $72,00 \%$ & $71,39 \%$ & $99,14 \%$ & 28 & Decrescentes \\
\hline SANTA MARIA & $68,11 \%$ & $70,02 \%$ & $70,02 \%$ & $97,27 \%$ & 29 & Crescentes \\
\hline COOPERALIANÇA & $65,17 \%$ & $65,52 \%$ & $65,52 \%$ & $99,47 \%$ & 30 & Crescentes \\
\hline CHESP & $64,59 \%$ & $71,46 \%$ & $71,46 \%$ & $90,38 \%$ & 31 & Crescentes \\
\hline CEMIG & $63,52 \%$ & $100,00 \%$ & $63,52 \%$ & $63,52 \%$ & 32 & Decrescentes \\
\hline CEPISA & $62,81 \%$ & $62,92 \%$ & $62,92 \%$ & $99,83 \%$ & 33 & Crescentes \\
\hline SULGIPE & $61,98 \%$ & $64,45 \%$ & $64,45 \%$ & $96,16 \%$ & 34 & Crescentes \\
\hline CAIUA & $60,74 \%$ & $60,80 \%$ & $60,74 \%$ & $99,91 \%$ & 35 & Decrescentes \\
\hline BRAGANTINA & $60,61 \%$ & $60,67 \%$ & $60,67 \%$ & $99,90 \%$ & 36 & Crescentes \\
\hline ENE. SERGIPE & $59,78 \%$ & $59,86 \%$ & $59,86 \%$ & $99,88 \%$ & 37 & Crescentes \\
\hline ELETROACRE & $56,92 \%$ & $57,60 \%$ & $57,60 \%$ & $98,83 \%$ & 38 & Crescentes \\
\hline CELESC & $56,75 \%$ & $69,33 \%$ & $56,75 \%$ & $81,85 \%$ & 39 & Decrescentes \\
\hline NACIONAL & $55,11 \%$ & $55,31 \%$ & $55,11 \%$ & $99,64 \%$ & 40 & Decrescentes \\
\hline CFLO & $53,75 \%$ & $53,84 \%$ & $53,75 \%$ & $99,83 \%$ & 41 & Decrescentes \\
\hline COCEL & $53,74 \%$ & $54,89 \%$ & $54,89 \%$ & $97,92 \%$ & 42 & Crescentes \\
\hline VALE PARANAPANEMA & $52,43 \%$ & $52,46 \%$ & $52,46 \%$ & $99,95 \%$ & 43 & Crescentes \\
\hline IGUAÇU & $51,98 \%$ & $54,72 \%$ & $54,72 \%$ & $94,98 \%$ & 44 & Crescentes \\
\hline CERON & $51,94 \%$ & $52,03 \%$ & $52,03 \%$ & $99,82 \%$ & 45 & Crescentes \\
\hline CEB & $51,74 \%$ & $53,63 \%$ & $51,74 \%$ & $96,47 \%$ & 46 & Decrescentes \\
\hline CELPA & $51,33 \%$ & $51,36 \%$ & $51,36 \%$ & $99,95 \%$ & 47 & Crescentes \\
\hline DEMEI & $50,60 \%$ & $50,75 \%$ & $50,75 \%$ & $99,69 \%$ & 48 & Crescentes \\
\hline HIDROPAN & $50,36 \%$ & $50,58 \%$ & $50,58 \%$ & $99,58 \%$ & 49 & Crescentes \\
\hline ENE. NOVA FRIBURGO & $47,08 \%$ & $47,61 \%$ & $47,61 \%$ & $98,90 \%$ & 50 & Crescentes \\
\hline CEAL & $47,04 \%$ & $47,08 \%$ & $47,08 \%$ & $99,93 \%$ & 51 & Crescentes \\
\hline CEEE & $42,21 \%$ & $43,44 \%$ & $42,21 \%$ & $97,15 \%$ & 52 & Decrescentes \\
\hline DME-PC & $41,50 \%$ & $42,11 \%$ & $41,50 \%$ & $98,56 \%$ & 53 & Decrescentes \\
\hline AME & $41,36 \%$ & $45,80 \%$ & $41,36 \%$ & $90,31 \%$ & 54 & Decrescentes \\
\hline ELETROCAR & $38,09 \%$ & $41,87 \%$ & $41,87 \%$ & $90,97 \%$ & 55 & Crescentes \\
\hline FORCEL & $33,75 \%$ & $44,57 \%$ & $44,57 \%$ & $75,73 \%$ & 56 & Crescentes \\
\hline URUSSANGA & $31,52 \%$ & $40,45 \%$ & $40,45 \%$ & $77,92 \%$ & 57 & Crescentes \\
\hline JOAO CESA & $24,04 \%$ & $94,35 \%$ & $94,35 \%$ & $25,48 \%$ & 58 & Crescentes \\
\hline BOA VISTA & $21,15 \%$ & $21,21 \%$ & $21,15 \%$ & $99,68 \%$ & 59 & Decrescentes \\
\hline
\end{tabular}

Fonte: Elaboração Própria. 
Tabela 9 - Estatísticas descritivas da análise DEA

\begin{tabular}{|c|c|c|c|c|c|c|}
\hline $\begin{array}{l}\text { Retorno de } \\
\text { Escala }\end{array}$ & Média & $\begin{array}{l}\text { Desvio } \\
\text { Padrão }\end{array}$ & Mínimo & Mediana & Máximo & $\begin{array}{l}\mathrm{N}^{\mathrm{o}} \text { de Valores } \\
\text { Máximos }\end{array}$ \\
\hline CRS & $67,77 \%$ & $21,23 \%$ & $21,15 \%$ & $65,17 \%$ & $100,00 \%$ & 7 \\
\hline VRS & $72,64 \%$ & $21,71 \%$ & $21,21 \%$ & $71,77 \%$ & $100,00 \%$ & 11 \\
\hline IRS & $70,18 \%$ & $20,40 \%$ & $21,15 \%$ & $71,39 \%$ & $100,00 \%$ & 7 \\
\hline Escala & $93,96 \%$ & $11,77 \%$ & $25,48 \%$ & $98,83 \%$ & $100,00 \%$ & 7 \\
\hline
\end{tabular}

Fonte: Elaboração Própria.

firmas eficientes na análise de eficiência com retornos constantes de escala, retornos não decrescentes de escala e na análise de retornos de escala. A análise de retornos variáveis de escala encontrou onze firmas eficientes. Desta forma, no método DEA, estas firmas tomam a si mesmas como referência para o cálculo de suas eficiências. De forma que, dependendo da especificação, temos sete ou onze firmas competindo consigo mesmas, mostrando assim que o efeito ratchet afeta $11,86 \%$ ou $18,64 \%$ das DMUs analisadas.

As DMUs que são afetadas pelo efeito ratchet também são as firmas consideradas eficientes nas diferentes análises DEA. Como, na análise mais benevolente, apenas 18,64\% das firmas são eficientes, observa-se que a maioria das firmas não opera na fronteira de eficiência estimada. Caso todas as firmas fossem eficientes, seria possível fazer um economia de $\mathrm{R} \$ 3.915 .261 .000,00$ no OPEX. Esta seria uma economia de 24,77\% do total dos custos ponderados. Se todas as firmas atingissem a eficiência técnica pura, desconsiderando ganhos de eficiência de escala, seria possível economizar $\mathrm{R} \$ 3.011 .356,00$, uma economia de $19,05 \%$.

Em alguns estudos, calcula-se a economia possível como a diferença entre o custo operacional total e o custo operacional total das firmas vezes a média da eficiência das DMUs, como é o caso de Chen (2002). É necessário, porém, ponderar a possibilidade de economia de custo operacional, o escore de eficiência na orientação para insumo, pelo custo de cada firma. Caso a ineficiência fosse espalhada uniformemente por todas as firmas esperar-se-ia uma economia de $32,23 \%$. Todavia, como observa-se na tabela 8 , isso não ocorre. A ineficiência não é uniformemente distribuída, nem uniformemente disposta em faixas de custos operacionais. Desta forma, a eficiência do setor como um todo em transformar insumos em produtos difere da eficiência média das firmas.

A maioria das DMUs, 49,15\%, operam com retornos crescentes de escala. Neste caso o aumento da escala acarretaria em ganhos de eficiência. 23 DMUs, 38,98\%, operam com retornos decrescentes de escala, podendo ter ganhos de eficiência com diminuição do tamanho de suas operações. Apenas sete firmas, 11,86\%, operam com retornos constantes de escala, ou seja, em escala ótima. Pode ser observado os valores encontrados para as faixas de escala em que operam as DMUs na tabela 10.

Esses resultados apontam para a existência da possibilidade de ganhos de escala 
Tabela 10 - Retornos de Escala

\begin{tabular}{lrr}
\hline Tipos de Retornos & Números & Porcentagem \\
\hline Ótimo & 7 & $11.86 \%$ \\
Crescente & 29 & $49.15 \%$ \\
Decrescente & 23 & $38.98 \%$ \\
\hline
\end{tabular}

Fonte: Elaboração Própria.

com aquisições, fusões e alienações parciais. Esses resultados também indicam que a hipótese de retornos não decrescentes de escala não é adequada as distribuidoras elétricas brasileiras, já que 38,98\% destas apresentam retornos decrescentes. Esse resultado é contrário a hipótese utilizada por ANEEL (2015). 


\subsection{MDEA: Supereficiência}

A tabela 11 apresenta os resultados obtidos para análise das distribuidoras elétricas brasileiras a partir do método MDEA. Observa-se que as sete firmas consideradas eficientes nas especificações com retornos constantes e não decrescentes agora possuem escore de eficiência maior do que um, e ainda que é possível discriminar entre elas obtendo uma classificação completa, como descrito por Andersen e Petersen (1993). Essa diferenciação permite um esquema de regulação, como o proposto por Agrell et al. (2005), em que as distribuidoras recebem parte dos benefícios por terem sido supereficientes, elevando, dessa forma, o incentivo para inovação.

Os escores de eficiência maior que um, na tabela acima de 100,00\%, representam as firmas supereficientes. Estas firmas podem aumentar seu OPEX pelo seu escore de eficiência e mesmo assim continuarem a serem eficientes na análise. Estas firmas não tem incentivo sobre o modelo DEA a buscarem ganhos de eficiência pois estes ganhos não seriam observados pelo regulador.

A tabela 12 apresenta as estatísticas descritivas da análise MDEA sobre todas as DMUs analisadas. Foram calculados a média, o desvio-padrão, o valor mínimo, a mediana e o valor máximo. São apresentadas as estatísticas da análise de eficiência em retornos de escala diferentes: retornos constantes (CRS), retornos variáveis (VRS), retornos não decrescentes (IRS).

Como observado por Andersen e Petersen (1993) conclui-se que o método DEA com supereficiência foi capaz de discriminar as firmas eficientes, Obteve-se uma classificação completa das firmas, A capacidade de classificar as DMU auxilia na busca de melhora da performance pelo regulador (ZANBOORI et al., 2014),

Observa-se um aumento da média e dos desvios padrões das eficiências observadas em relação ao modelo DEA original. Este resultado é decorrente da característica do método que não limita os resultados da DMUs eficientes em um. A média de eficiência das DMUs, considerando retornos constantes, é de 69,35\%; considerando retornos variáveis, é de $76,86 \%$ e considerando retornos não decrescentes de $73,04 \%$.

O desvio-padrão do escore de eficiência varia de acordo com a especificação usada no método. Considerando retornos constantes, o desvio é de $24,45 \%$; Já para retornos variáveis o desvio é de 30,05\%, atingindo 27,04\% para retornos variáveis.. Observa-se uma maior heterogeneidade das firmas ao se usar os escores de supereficiência. Isso ocorre pois as firmas eficientes no método original não estão mais restritas ao escore de eficiência um.

O valor mínimo de eficiência continuou o mesmo nas duas avaliações devido a análise de supereficiência não alterar o escore das firmas ineficientes. O valor máximo de eficiência aumentou devido ao método DEA supereficiência permitir que as firmas efici- 
Tabela 11 - DEA supereficiência

\begin{tabular}{|c|c|c|c|c|}
\hline Distribuidora & CRS & VRS & IRS & Classificação \\
\hline CELTINS & $140,10 \%$ & $140,12 \%$ & $140,12 \%$ & 1 \\
\hline JAGUARI & $129,10 \%$ & $130,59 \%$ & $129,10 \%$ & 2 \\
\hline RGE & $113,33 \%$ & $114,86 \%$ & $113,33 \%$ & 3 \\
\hline COELBA & $103,09 \%$ & $158,71 \%$ & $103,09 \%$ & 4 \\
\hline COELCE & $103,07 \%$ & $103,10 \%$ & $103,10 \%$ & 5 \\
\hline COSERN & $102,56 \%$ & $103,01 \%$ & $102,56 \%$ & 6 \\
\hline MUXFELDT & $101,97 \%$ & $177,53 \%$ & $177,53 \%$ & 7 \\
\hline PIRATININGA & $98,28 \%$ & $109,59 \%$ & $98,28 \%$ & 8 \\
\hline CEMAR & $92,50 \%$ & $92,58 \%$ & $92,58 \%$ & 9 \\
\hline CELPE & $92,45 \%$ & $94,45 \%$ & $92,45 \%$ & 10 \\
\hline BANDEIRANTE & $90,94 \%$ & $93,41 \%$ & $90,94 \%$ & 11 \\
\hline AES SUL & $90,41 \%$ & $97,63 \%$ & $90,41 \%$ & 12 \\
\hline CPFL PAULISTA & $87,71 \%$ & $111,42 \%$ & $87,71 \%$ & 13 \\
\hline ELEKTRO & $85,33 \%$ & $95,09 \%$ & $85,33 \%$ & 14 \\
\hline MOCOCA & $84,31 \%$ & $91,19 \%$ & $91,19 \%$ & 15 \\
\hline ENE. PARAÍBA & $84,18 \%$ & $84,40 \%$ & $84,40 \%$ & 16 \\
\hline LIGHT & $83,40 \%$ & $96,06 \%$ & $83,40 \%$ & 17 \\
\hline CSPE & $82,23 \%$ & $85,85 \%$ & $85,85 \%$ & 18 \\
\hline CEMAT & $81,14 \%$ & $89,33 \%$ & $81,14 \%$ & 19 \\
\hline ELETROPAULO & $80,28 \%$ & $100,00 \%$ & $80,28 \%$ & 20 \\
\hline ENE. BORBOREMA & $78,20 \%$ & $78,27 \%$ & $78,27 \%$ & 21 \\
\hline NOVA PALMA & $77,35 \%$ & $96,21 \%$ & $96,21 \%$ & 22 \\
\hline ESCELSA & $75,39 \%$ & $75,96 \%$ & $75,39 \%$ & 23 \\
\hline CELG & $74,47 \%$ & $82,94 \%$ & $74,47 \%$ & 24 \\
\hline AMPLA & $73,33 \%$ & $75,29 \%$ & $73,33 \%$ & 25 \\
\hline ENE. MINAS GERAIS & $71,95 \%$ & $72,67 \%$ & $72,67 \%$ & 26 \\
\hline SANTA CRUZ & $71,72 \%$ & $71,77 \%$ & $71,77 \%$ & 27 \\
\hline ENERSUL & $71,39 \%$ & $72,00 \%$ & $71,39 \%$ & 28 \\
\hline SANTA MARIA & $68,11 \%$ & $70,02 \%$ & $70,02 \%$ & 29 \\
\hline COOPERALIANÇA & $65,17 \%$ & $65,52 \%$ & $65,52 \%$ & 30 \\
\hline CHESP & $64,59 \%$ & $71,46 \%$ & $71,46 \%$ & 31 \\
\hline CEMIG & $63,52 \%$ & $100,00 \%$ & $63,52 \%$ & 32 \\
\hline CEPISA & $62,81 \%$ & $62,92 \%$ & $62,92 \%$ & 33 \\
\hline SULGIPE & $61,98 \%$ & $64,45 \%$ & $64,45 \%$ & 34 \\
\hline CAIUA & $60,74 \%$ & $60,80 \%$ & $60,74 \%$ & 35 \\
\hline BRAGANTINA & $60,61 \%$ & $60,67 \%$ & $60,67 \%$ & 36 \\
\hline ENE. SERGIPE & $59,78 \%$ & $59,86 \%$ & $59,86 \%$ & 37 \\
\hline ELETROACRE & $56,92 \%$ & $57,60 \%$ & $57,60 \%$ & 38 \\
\hline CELESC & $56,75 \%$ & $69,33 \%$ & $56,75 \%$ & 39 \\
\hline NACIONAL & $55,11 \%$ & $55,31 \%$ & $55,11 \%$ & 40 \\
\hline CFLO & $53,75 \%$ & $53,84 \%$ & $53,75 \%$ & 41 \\
\hline COCEL & $53,74 \%$ & $54,89 \%$ & $54,89 \%$ & 42 \\
\hline VALE PARANAPANEMA & $52,43 \%$ & $52,46 \%$ & $52,46 \%$ & 43 \\
\hline IGUAÇU & $51,98 \%$ & $54,72 \%$ & $54,72 \%$ & 44 \\
\hline CERON & $51,94 \%$ & $52,03 \%$ & $52,03 \%$ & 45 \\
\hline CEB & $51,74 \%$ & $53,63 \%$ & $51,74 \%$ & 46 \\
\hline CELPA & $51,33 \%$ & $51,36 \%$ & $51,36 \%$ & 47 \\
\hline DEMEI & $50,60 \%$ & $50,75 \%$ & $50,75 \%$ & 48 \\
\hline HIDROPAN & $50,36 \%$ & $50,58 \%$ & $50,58 \%$ & 49 \\
\hline ENE. NOVA FRIBURGO & $47,08 \%$ & $47,61 \%$ & $47,61 \%$ & 50 \\
\hline CEAL & $47,04 \%$ & $47,08 \%$ & $47,08 \%$ & 51 \\
\hline CEEE & $42,21 \%$ & $43,44 \%$ & $42,21 \%$ & 52 \\
\hline DME-PC & $41,50 \%$ & $42,11 \%$ & $41,50 \%$ & 53 \\
\hline AME & $41,36 \%$ & $45,80 \%$ & $41,36 \%$ & 54 \\
\hline ELETROCAR & $38,09 \%$ & $41,87 \%$ & $41,87 \%$ & 55 \\
\hline FORCEL & $33,75 \%$ & $44,57 \%$ & $44,57 \%$ & 56 \\
\hline URUSSANGA & $31,52 \%$ & $40,45 \%$ & $40,45 \%$ & 57 \\
\hline JOAO CESA & $24,04 \%$ & $94,35 \%$ & $94,35 \%$ & 58 \\
\hline BOA VISTA & $21,15 \%$ & $21,21 \%$ & $21,15 \%$ & 59 \\
\hline
\end{tabular}

Fonte: Elaboração Própria, 
Tabela 12 - Estatísticas descritivas da análise DEA supereficiência

\begin{tabular}{|c|c|c|c|c|c|c|}
\hline $\begin{array}{l}\text { Retorno de } \\
\text { Escala }\end{array}$ & Média & $\begin{array}{l}\text { Desvio } \\
\text { Padrão }\end{array}$ & Mínimo & Mediana & Máximo & $\begin{array}{l}\mathrm{N}^{\mathrm{o}} \text { Valores } \\
\text { Máximos }\end{array}$ \\
\hline CRS & $69,35 \%$ & $24,45 \%$ & $21,15 \%$ & $65,17 \%$ & $140,10 \%$ & 1 \\
\hline VRS & $76,86 \%$ & $30,05 \%$ & $21,21 \%$ & $71,77 \%$ & $177,53 \%$ & 1 \\
\hline IRS & $73,04 \%$ & $27,04 \%$ & $21,15 \%$ & $71,39 \%$ & $177,53 \%$ & 1 \\
\hline
\end{tabular}

Fonte: Elaboração Própria.

entes obtenham um escore de eficiência maior que um. Os valores máximos em qualquer especificação DEA são de 100,00\% enquando foi encontrado um valor máximo de 140,10\% para retornos constantes de escala e de 177,53\% para retornos variáveis e retornos não decrescentes de escala. Isto significa que estas firmas podem aumentar seu OPEX e continuarem sendo eficientes.

Existe a eliminação do efeito ratchet pela firma ser excluída da sua matriz de comparação no método MDEA. Dessa forma, ao incorporar as informações adicionais obtidas pelo método MDEA, o fator X seria capaz de gerar incentivos para as firmas supereficientes. Uma das formas para se obter isto seria permitir que as firmas obtivessem partes dos ganhos por serem superiores a seu conjunto de comparação (AGRELL et al., 2005). Assim sendo, as firmas que têm incentivos a aumentar seus custos segundo o método DEA tradicional teriam incentivos para melhorar seus resultados. 


\subsection{Segundo estágio}

Os resultados das regressões MQO e MQO com erros robustos sobre os escores de eficiência obtidos através do método DEA e MDEA com retornos constantes e retornos variáveis de escala podem ser observados na tabela 13.

Tabela 13 - Regressões sobre escores DEA: MQO e MQO com erros robustos

\begin{tabular}{|c|c|c|c|c|c|c|c|c|}
\hline & \multicolumn{8}{|c|}{ Escores de eficiência: } \\
\hline & \multicolumn{2}{|c|}{ DEA: CRS } & \multicolumn{2}{|c|}{ DEA: VRS } & \multicolumn{2}{|c|}{ MDEA: CRS } & \multicolumn{2}{|c|}{ MDEA: VRS } \\
\hline & MQO & $\begin{array}{c}\text { Erros } \\
\text { Robustos }\end{array}$ & $\mathrm{MQO}$ & $\begin{array}{c}\text { Erros } \\
\text { Robustos }\end{array}$ & MQO & $\begin{array}{c}\text { Erros } \\
\text { Robustos }\end{array}$ & MQO & $\begin{array}{c}\text { Erros } \\
\text { Robustos }\end{array}$ \\
\hline & (1) & $(2)$ & (3) & $(4)$ & (5) & $(6)$ & $(7)$ & $(8)$ \\
\hline Complexidade & $\begin{array}{l}0.306 \\
(0.316)\end{array}$ & $\begin{array}{c}0.306 \\
(0.222)\end{array}$ & $\begin{array}{l}0.500 \\
(0.336)\end{array}$ & $\begin{array}{l}0.500^{*} \\
(0.261)\end{array}$ & $\begin{array}{c}0.243 \\
(0.377)\end{array}$ & $\begin{array}{c}0.243 \\
(0.283)\end{array}$ & $\begin{array}{l}0.400 \\
(0.516)\end{array}$ & $\begin{array}{c}0.400 \\
(0.353)\end{array}$ \\
\hline Privado & $\begin{array}{l}0.192^{* * *} \\
(0.060)\end{array}$ & $\begin{array}{c}0.192^{* * *} \\
(0.041)\end{array}$ & $\begin{array}{l}0.175^{* * *} \\
(0.063)\end{array}$ & $\begin{array}{c}0.175^{* * *} \\
(0.059)\end{array}$ & $\begin{array}{l}0.222^{* * *} \\
(0.071)\end{array}$ & $\begin{array}{c}0.222^{* * *} \\
(0.047)\end{array}$ & $\begin{array}{l}0.236^{* *} \\
(0.097)\end{array}$ & $\begin{array}{c}0.236^{* * *} \\
(0.073)\end{array}$ \\
\hline Nordeste & $\begin{array}{l}0.028 \\
(0.137)\end{array}$ & $\begin{array}{c}0.028 \\
(0.098)\end{array}$ & $\begin{array}{l}-0.060 \\
(0.146)\end{array}$ & $\begin{array}{l}-0.060 \\
(0.115)\end{array}$ & $\begin{array}{l}-0.006 \\
(0.163)\end{array}$ & $\begin{array}{l}-0.006 \\
(0.128)\end{array}$ & $\begin{array}{l}-0.018 \\
(0.223)\end{array}$ & $\begin{array}{l}-0.018 \\
(0.165)\end{array}$ \\
\hline Norte & $\begin{array}{l}-0.270^{*} \\
(0.158)\end{array}$ & $\begin{array}{c}-0.270^{* *} \\
(0.130)\end{array}$ & $\begin{array}{l}-0.316^{*} \\
(0.168)\end{array}$ & $\begin{array}{c}-0.316^{* *} \\
(0.138)\end{array}$ & $\begin{array}{l}-0.366^{*} \\
(0.189)\end{array}$ & $\begin{array}{c}-0.366^{* *} \\
(0.177)\end{array}$ & $\begin{array}{l}-0.355 \\
(0.258)\end{array}$ & $\begin{array}{c}-0.355^{*} \\
(0.184)\end{array}$ \\
\hline Sudeste & $\begin{array}{l}-0.001 \\
(0.087)\end{array}$ & $\begin{array}{l}-0.001 \\
(0.066)\end{array}$ & $\begin{array}{l}0.008 \\
(0.093)\end{array}$ & $\begin{array}{c}0.008 \\
(0.076)\end{array}$ & $\begin{array}{l}-0.037 \\
(0.104)\end{array}$ & $\begin{array}{l}-0.037 \\
(0.095)\end{array}$ & $\begin{array}{l}-0.051 \\
(0.143)\end{array}$ & $\begin{array}{l}-0.051 \\
(0.110)\end{array}$ \\
\hline Sul & $\begin{array}{l}-0.120 \\
(0.093)\end{array}$ & $\begin{array}{c}-0.120^{*} \\
(0.072)\end{array}$ & $\begin{array}{l}-0.056 \\
(0.099)\end{array}$ & $\begin{array}{l}-0.056 \\
(0.082)\end{array}$ & $\begin{array}{l}-0.181 \\
(0.111)\end{array}$ & $\begin{array}{c}-0.181^{*} \\
(0.101)\end{array}$ & $\begin{array}{l}-0.096 \\
(0.151)\end{array}$ & $\begin{array}{l}-0.096 \\
(0.112)\end{array}$ \\
\hline Vegetação & $\begin{array}{l}0.239 \\
(0.173)\end{array}$ & $\begin{array}{c}0.239 \\
(0.177)\end{array}$ & $\begin{array}{l}0.233 \\
(0.184)\end{array}$ & $\begin{array}{c}0.233 \\
(0.179)\end{array}$ & $\begin{array}{l}0.349^{*} \\
(0.206)\end{array}$ & $\begin{array}{c}0.349 \\
(0.229)\end{array}$ & $\begin{array}{l}0.185 \\
(0.281)\end{array}$ & $\begin{array}{c}0.185 \\
(0.267)\end{array}$ \\
\hline Descargas & $\begin{array}{l}0.016 \\
(0.014)\end{array}$ & $\begin{array}{l}0.016^{*} \\
(0.009)\end{array}$ & $\begin{array}{l}0.017 \\
(0.015)\end{array}$ & $\begin{array}{l}0.017^{*} \\
(0.010)\end{array}$ & $\begin{array}{c}0.016 \\
(0.017)\end{array}$ & $\begin{array}{c}0.016 \\
(0.011)\end{array}$ & $\begin{array}{l}0.017 \\
(0.023)\end{array}$ & $\begin{array}{c}0.017 \\
(0.012)\end{array}$ \\
\hline Precipitação & $\begin{array}{l}-0.0001 \\
(0.0002)\end{array}$ & $\begin{array}{l}-0.0001 \\
(0.0002)\end{array}$ & $\begin{array}{l}-0.0002 \\
(0.0002)\end{array}$ & $\begin{array}{l}-0.0002 \\
(0.0002)\end{array}$ & $\begin{array}{l}-0.00004 \\
(0.0002)\end{array}$ & $\begin{array}{c}-0.00004 \\
(0.0002)\end{array}$ & $\begin{array}{l}-0.0001 \\
(0.0003)\end{array}$ & $\begin{array}{l}-0.0001 \\
(0.0002)\end{array}$ \\
\hline Constante & $\begin{array}{l}0.515^{* *} \\
(0.235)\end{array}$ & $\begin{array}{c}0.515^{* *} \\
(0.221)\end{array}$ & $\begin{array}{l}0.629^{* *} \\
(0.250)\end{array}$ & $\begin{array}{c}0.629^{* * *} \\
(0.242)\end{array}$ & $\begin{array}{l}0.462^{*} \\
(0.281)\end{array}$ & $\begin{array}{l}0.462^{*} \\
(0.260)\end{array}$ & $\begin{array}{l}0.566 \\
(0.384)\end{array}$ & $\begin{array}{l}0.566^{*} \\
(0.321)\end{array}$ \\
\hline Observações & 59 & 59 & 59 & 59 & 59 & 59 & 59 & 59 \\
\hline $\mathrm{R}^{2}$ & 0.441 & 0.441 & 0.396 & 0.396 & 0.401 & 0.401 & 0.259 & 0.259 \\
\hline $\mathrm{R}^{2}$ Ajustado & 0.339 & 0.339 & 0.285 & 0.285 & 0.291 & 0.291 & 0.123 & 0.123 \\
\hline $\begin{array}{l}\text { Erros Padrão Residuais } \\
(\mathrm{df}=49)\end{array}$ & 0.173 & 0.173 & 0.184 & 0.184 & 0.206 & 0.206 & 0.281 & 0.281 \\
\hline $\begin{array}{l}\text { Estatística } \mathrm{F}(\mathrm{df}=9 \\
49)\end{array}$ & $4.303^{* * *}$ & $4.303^{* * *}$ & $3.570^{* * *}$ & $3.570^{* * *}$ & $3.646^{* * *}$ & $3.646^{* * *}$ & $1.908^{*}$ & $1.908^{*}$ \\
\hline
\end{tabular}

Foram realizadas também regressões tobit sobre os escores de eficiência obtidos através do método DEA com retornos constantes e retornos variáveis de escala. Os resultados das regressões podem ser observados na tabela 14.

Os resultados da regressão Tobit são semelhantes aos obtidos a partir das regressões utilizando MQO e MQO com erros robustos. Precipitação tem o sinal esperado mas não é estatisticamente significativo. Descargas e vegetação apresentam sinal diferentes do 
Tabela 14 - Regressões sobre escores DEA: TOBIT

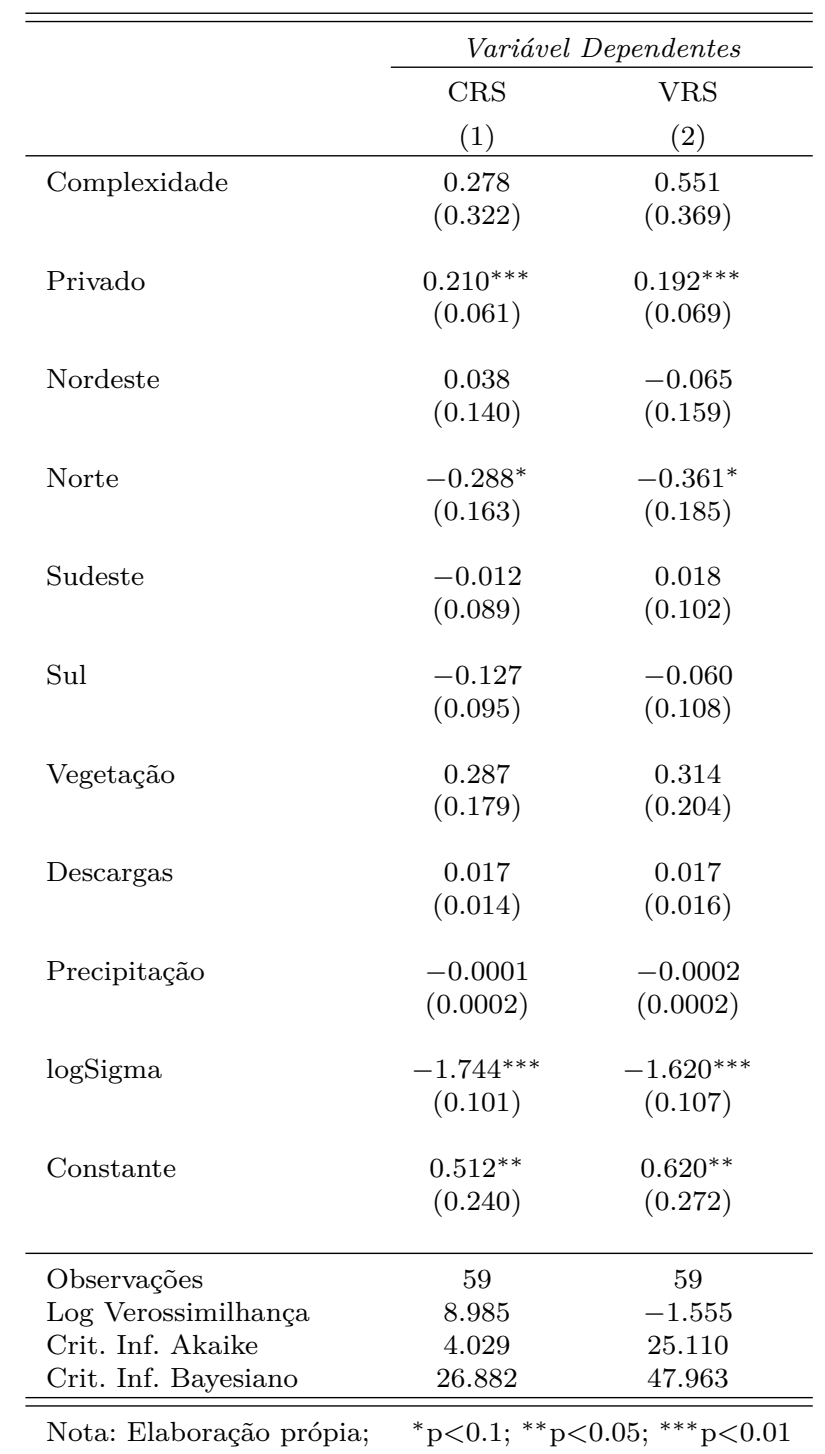

esperado mas não são estatisticamente significativos, com exceção da variável vegetação para a regressão MQO com erros robustos sore os escores MDEA CRS e para a variável descargas para as regressões MQO com erros robustos dos escores de eficiência obtidos pelo DEA. O valor encontrado para complexidade é positivo, o que é diferente de esperado, mas não significativo, exceto quando utilizado MQO com erros robusto nos escores de eficiência obtidos com DEA VRS. Çelen (2013) encontra resultados semelhantes para o coeficiente de complexidade na sua análise das distribuidoras da Turquia.

Verifica-se que existe uma diferença significativa de eficiência entre firmas privadas e firmas públicas. Este resultado é consonante à grande parte da literatura sobre a eficiência das firmas privadas e públicas no Brasil (FERNANDES; RESENDE FILHO, 2017), (BOENTE; LUSTOSA, 2016), (TANNURI-PIANTO et al., 2009) e (JACOB, 2016). Segundo as estimativas encontradas espera-se que as firmas privadas sejam até 23,6\% mais eficientes do que as firmas controladas pelo governo. 
Verificou-se também que a região da firma é relevante para sua eficiência. Não há diferença significativa, na maioria das análises, entre as distribuidoras da região Sul, Sudeste e Nordeste com a região Centro-Oeste, escolhida como base, porém as distribuidoras da região Norte são menos eficientes do que as distribuidoras da região Centro-Oeste. Uma explicação possível para a diferença de eficiência seria as limitações de infraestrutura da região ou necessidade de se atender áreas remotas. 


\section{Conclusão}

O presente trabalho analisou a eficiência técnica das distribuidoras de energia elétrica brasileira por meio da análise em dois estágios com os métodos DEA e MDEA. O trabalho contribui para a literatura ao inovar utilizando o método MDEA e analisando os determinantes da eficiência. Vale ressaltar que o conceito de eficiência utilizado nesta dissertação é de eficiência técnica, ou seja, da eficiência da entidade analisada em transformar insumos em produtos.

O método DEA permite caracterizar as firmas de acordo com sua eficiência. A média de eficiência técnica das firmas é consideravelmente baixa, variando de 69,35\% a $76,86 \%$, dependendo da especificação do modelo. Observa-se uma grande variação entre distribuidoras, a qual se nota pelo alto desvio-padrão das medidas de eficiência, entre $20 \%$ e 21\%, dependendo da especificação do modelo. A eficiência de escala das firmas brasileiras é superior à eficiência técnica pura com menor variação.

Verificou-se também a existência de uma diversidade de tipos de retornos de escala. Nota-se que 38,98\% das distribuidoras apresentando retornos decrescentes, dado que vai de encontro à hipótese utilizada por ANEEL (2015), que considera que as firmas apresentam retornos não decrescentes. Dessa forma, a presente observação pode ser utilizada pelo regulador do setor elétrico brasileiro para melhor descrever o setor em futuros ciclos de revisão tarifária.

O estudo observou que existe um grande potencial para economia de custos segundo os escores de eficiência obtidos através do método. A economia pode chegar a quase quatro bilhões de reais por ano caso as distribuidoras fossem eficientes. Esse alto valor indicar que ainda existe espaço para ganhos de eficiência das distribuidoras, entretanto o espaço para ganhos de eficiência a partir de mudanças de escala é reduzido, sendo a maioria dos ganhos possíveis de eficiência técnica pura.

A regulação feita utilizando o método DEA gera um porcentual considerável de firmas tendo como referencial a si mesmas: 18,64\%,11,86\% e 11,86\%, considerando, respectivamente, os método DEA com retornos variáveis, constantes e não decrescentes de escala respectivamente. Isso gera o efeito ratchet que deve ser evitado na regulação.

O método MDEA auxilia a resolução de dois problemas da análise DEA: o efeito ratchet e a classificação das firmas. No método MDEA, nenhuma das firmas compete consigo mesma, anulando, desta forma, o efeito ratchet e obtendo uma classificação completa das DMUs. A utilização desse método na regulação das distribuidoras elétricas brasileiras, permitiria um ganho de informações assim como um mecanismo para gerar incentivos as firmas consideradas eficientes pelo método DEA Agrell et al. (2005). Desta forma, e como 
não a perda de informações em relação ao uso do método DEA tradicional, recomenda-se a utilização deste método pela agência reguladora como suporte para a regulação do setor.

A análise em segundo estágio apresenta resultados condizentes com os encontrados na literatura. A maioria das variáveis explicativas escolhidas apresentou resultados não significativos. Este padrão é observado nos trabalhos de Fernandes e Resende Filho (2017) e Çelen (2013). Propriedade privada e a dummy para região Norte deram resultados significativos em todas as regressões realizadas. As distribuidoras privadas apresentam maior eficiência que as distribuidoras públicas enquanto as distribuidoras do Norte são significativamente menos eficientes que as distribuidoras do Centro-Oeste. Uma possível razão para a diferença entre firmas privadas e públicas é a diferença na composição dos gastos dos dois grupos. A diferença da região Norte pode ocorrer pela necessidade de atender áreas isoladas ou por limitações de infraestrutura.

É necessário cuidado com os resultados obtidos. As distribuidoras elétricas não foram divididas entre privadas e públicas aleatoriamente não podendo estabelecer uma relação de causalidade a partir dos resultados obtidos. Entretanto, observa-se a necessidade e espaço para melhoras técnicas. O resultado da dummy da região Norte deve ser mais estudado. É possível que essa diferença ocorra por características diferentes das distribuidoras da região ou da função de produção para esta área. É necessário portanto saber se os ganhos de eficiência possíveis para as distribuidoras desta região estão limitados e, caso estejam, observar qual a real fronteira de possibilidades de produção delas e não compara-las com distribuidoras que não sejam realmente comparáveis, penalizando-as por fatores ambientais.

Sugere-se que pesquisas futuras utilizem a composição de capital para a análise das distribuidoras elétricas brasileiras. Acredita-se que com esses dados seria possível realizar a análise de longo e curto prazo do setor. Outra sugestão é a utilização do método MDEA para a análise de outliers, como proposta por Banker et al. (2017). Por fim, seria possível complementar a análise em segundo estágio utilizando outras metodologias para as regressões como a regressão com bootstrap proposta por Simar e Wilson (2007). 


\section{Referências}

ABRADEE. Associação Brasileira de Distribuição de Energia Elétrica - ABRADEE. 2017. <http://www.abradee.com.br/>. Accessed: 2017-08-30.

AGRELL, P. J.; BOGETOFT, P.; TIND, J. Dea and dynamic yardstick competition in scandinavian electricity distribution. Journal of Productivity Analysis, Springer, v. 23, n. 2, p. 173-201, 2005.

ANDERSEN, P.; PETERSEN, N. C. A procedure for ranking efficient units in data envelopment analysis. Management science, INFORMS, v. 39, n. 10, p. 1261-1264, 1993.

ANDRADE, G. N. de et al. Evaluating electricity distributors efficiency using self-organizing map and data envelopment analysis. IEEE Latin America Transactions, IEEE, v. 12, n. 8, p. 1464-1472, 2014.

ANEEL. Metodologia de cálculo dos custos operacionais. Nota Técnica no 101/2011SRM/SGT/ANEEL, 2011.

ANEEL. Metodologia de custos operacionais. Nota Técnica $n^{\circ}$ 66/2015SRM/SGT/ANEEL, 2015.

ARCOS-VARGAS, A.; NÚÑEZ-HERNÁNDEZ, F.; VILLA-CARO, G. A dea analysis of electricity distribution in spain: An industrial policy recommendation. Energy Policy, Elsevier, v. 102, p. 583-592, 2017.

BANKER, R. D.; CHANG, H. The super-efficiency procedure for outlier identification, not for ranking efficient units. European Journal of Operational Research, Elsevier, v. 175, n. 2, p. 1311-1320, 2006.

BANKER, R. D.; CHANG, H.; ZHENG, Z. On the use of super-efficiency procedures for ranking efficient units and identifying outliers. Annals of Operations Research, Springer, v. 250, n. 1, p. 21-35, 2017.

BANKER, R. D.; CHARNES, A.; COOPER, W. W. Some models for estimating technical and scale inefficiencies in data envelopment analysis. Management science, INFORMS, v. 30, n. 9, p. 1078-1092, 1984.

BANKER, R. D.; NATARAJAN, R. Evaluating contextual variables affecting productivity using data envelopment analysis. Operations research, INFORMS, v. 56, n. 1, p. 48-58, 2008.

BATOR, F. M. The anatomy of market failure. The quarterly journal of economics, MIT Press, v. 72, n. 3, p. 351-379, 1958.

BOENTE, D. R.; LUSTOSA, P. R. B. Um estudo comparativo da eficiência de distribuidoras brasileiras de energia eletrica privas de pu. Revista Ambiente Contabil, Universidade Federal do Rio Grande do Norte, Departamento de Ciências Contábeis, v. 8, n. 2, p. 263, 2016. 
BOGETOFT, P.; OTTO, L. Benchmarking with Dea, Sfa, and R. [S.l.]: Springer Science \& Business Media, 2010. v. 157.

BOGETOFT, P.; OTTO, L. Benchmarking with DEA and SFA. [S.1.], 2015. R package version 0.26 .

BRASIL. Agência nacional de energia elétrica - ANEEL. 2017. < http://www.aneel.gov. br/>. Accessed: 2017-08-30.

ÇELEN, A. Efficiency and productivity (tfp) of the turkish electricity distribution companies: An application of two-stage (dea\&tobit) analysis. Energy Policy, Elsevier, v. 63 , p. $300-310,2013$.

CHARNES, A. et al. Data envelopment analysis: Theory, methodology, and applications. [S.l.]: Springer Science \& Business Media, 2013.

CHARNES, A.; COOPER, W. W.; RHODES, E. Measuring the efficiency of decision making units. European journal of operational research, Elsevier, v. 2, n. 6, p. 429-444, 1978.

CHEN, T.-y. An assessment of technical efficiency and cross-efficiency in taiwan's electricity distribution sector. European Journal of Operational Research, Elsevier, v. 137, n. 2, p. 421-433, 2002.

CHEN, Y. Measuring super-efficiency in dea in the presence of infeasibility. European Journal of Operational Research, Elsevier, v. 161, n. 2, p. 545-551, 2005.

COELLI, T. J. et al. An introduction to efficiency and productivity analysis. [S.1.]: Springer Science \& Business Media, 2005.

CONSTANT, R. dos S. et al. Brazilian electricity distributors efficiency index based on non radial efficiency. IEEE Latin America Transactions, IEEE, v. 15, n. 9, p. 1657-1663, 2017.

COOK, W. D.; SEIFORD, L. M. Data envelopment analysis (dea)-thirty years on. European journal of operational research, Elsevier, v. 192, n. 1, p. 1-17, 2009.

DAHL, D. B. xtable: Export tables to latex or html, 2014. $R$ package version, p. 1-7, 2015 .

EMROUZNEJAD, A.; YANG, G.-1. A survey and analysis of the first 40 years of scholarly literature in dea: 1978-2016. Socio-Economic Planning Sciences, Elsevier, 2017.

ESPITIA-ESCUER, M.; GARCÍA-CEBRIÁN, L. I. Comparison of efficiency measures for spanish first division football teams using data envelopment and stochastic frontier analyses. Atlantic Review of Economics, A Coruña: Colegio de Economistas de A Coruña, v. 2, p. 1-28, 2014.

FERNANDES, D. de P.; RESENDE FILHO, M. d. A. Eficiência de custos operacionais das companhias de distribuição de energia elétrica (cdees) no brasil: Uma aplicação (dea \& tobit) em dois estágios. 2017.

HENNINGSEN, A. Estimating Censored Regression Models in R using the censReg Package. $R$ package vignettes collection, v. 5, n. 2, p. 12, 2010. 
HENNINGSEN, A. censReg: Censored Regression (Tobit) Models. [S.1.], 2017. R package version 0.5-26. Disponível em: <https://CRAN.R-project.org/package=censReg $>$.

HLAVAC, M. stargazer: Well-Formatted Regression and Summary Statistics

Tables. Cambridge, USA, 2015. R package version 5.2. Disponível em: < http:

/ /CRAN.R-project.org/package=stargazer $>$.

JACOB, F. E. J. Avaliação das demonstrações contabeis das distribuidoras de energia eletrica para estuda da eficiêcia comparativa usando analise por envoltorio de dados. 2016.

JAMASB, T.; POLLITT, M. Benchmarking and regulation: International electricity experience. Utilities Policy, v. 9, n. 3, p. 107-130, 2001. ISSN 09571787.

JI, Y.-b.; LEE, C. et al. Data envelopment analysis. The Stata Journal, v. 10, n. 2, p. 267-280, 2010.

KHODABAKHSHI, M. An output oriented super-efficiency measure in stochastic data envelopment analysis: Considering iranian electricity distribution companies. Computers E Industrial Engineering, Elsevier, v. 58, n. 4, p. 663-671, 2010.

LEME, R. C. et al. Design of experiments applied to environmental variables analysis in electricity utilities efficiency: The brazilian case. Energy Economics, Elsevier, v. 45, p. 111-119, 2014.

LI, K.; LIN, B. The improvement gap in energy intensity: Analysis of china's thirty provincial regions using the improved dea (data envelopment analysis) model. Energy, Elsevier, v. 84, p. 589-599, 2015.

LIU, J. S.; LU, L. Y.; LU, W.-M. Research fronts in data envelopment analysis. Omega, Elsevier, v. 58, p. 33-45, 2016.

LOPES, A. L. M. et al. Critical evalutaion of the efficient costs assessment model used in the regulation of brazilian energy distribution service operator. Revista Gestão $\&$ Tecnologia, v. 16, n. 3, 2016.

LOVELL, C. Recent developments in productivity analysis. Pacific Economic Review, Wiley Online Library, v. 21, n. 4, p. 417-444, 2016.

LOVELL, C.; ROUSE, A. Equivalent standard dea models to provide super-efficiency scores. Journal of the Operational Research Society, Springer, v. 54, n. 1, p. 101-108, 2003 .

LOVELL, C. K.; WALTERS, L. C.; WOOD, L. L. Stratified models of education production using modified dea and regression analysis. In: Data Envelopment Analysis: Theory, Methodology, and Applications. [S.l.: s.n.], 1994. p. 329-351.

MARTIĆ, M.; SAVIĆ, G. An application of dea for comparative analysis and ranking of regions in serbia with regards to social-economic development. European Journal of Operational Research, Elsevier, v. 132, n. 2, p. 343-356, 2001.

MCDONALD, J. Using least squares and tobit in second stage dea efficiency analyses. European Journal of Operational Research, Elsevier, v. 197, n. 2, p. 792-798, 2009. 
PÉREZ-REYES, R.; TOVAR, B. Measuring efficiency and productivity change (ptf) in the peruvian electricity distribution companies after reforms. Energy Policy, Elsevier, v. 37, n. 6, p. 2249-2261, 2009.

PESSANHA, J. F. M. et al. Avaliação dos custos operacionais eficientes das empresas de transmissão do setor elétrico brasileiro: uma proposta de adaptação do modelo dea adotado pela aneel. Pesquisa Operacional, SciELO Brasil, v. 30, n. 3, p. 521-545, 2010.

R Core Team. R: A Language and Environment for Statistical Computing. Vienna, Austria, 2017. Disponível em: <https://www.R-project.org/>.

REZENDE, S. M. de; PESSANHAB, J. F. M.; AMARALC, R. M. Avaliação cruzada das distribuidoras de energia elétrica. Production, SciELO Brasil, v. 24, n. 4, p. 820-832, 2014 .

SHLEIFER, A. A theory of yardstick competition. The RAND Journal of Economics, JSTOR, p. 319-327, 1985.

SIMAR, L.; WILSON, P. W. Estimation and inference in two-stage, semi-parametric models of production processes. Journal of econometrics, Elsevier, v. 136, n. 1, p. 31-64, 2007.

SOUZA, M.; SOUZA, R. C.; PESSANHA, J. F. M. Custos operacionais eficientes das distribuidoras de energia elétrica: um estudo comparativo dos modelos dea e sfa. Gestão E Produção, v. 17, n. 4, p. 653-667, 2010.

SOUZA, M. V. P. de et al. An application of data envelopment analysis to evaluate the efficiency level of the operational cost of brazilian electricity distribution utilities. Socio-Economic Planning Sciences, Elsevier, v. 48, n. 3, p. 169-174, 2014.

SUEYOSHI, T.; YUAN, Y.; GOTO, M. A literature study for dea applied to energy and environment. Energy Economics, Elsevier, v. 62, p. 104-124, 2017.

TANNURI-PIANTO, M. E.; SOUSA, M. d. C. S. d.; ARCOVERDE, F. D. Fronteiras de eficiência estocásticas para as empresas de distribuição de energia elétrica no brasil: uma análise de dados de painel. Estudos Econômicos (São Paulo), SciELO Brasil, v. 39, n. 1, p. 221-247, 2009.

TOVAR, B.; RAMOS-REAL, F. J.; ALMEIDA, E. F. D. Firm size and productivity. evidence from the electricity distribution industry in brazil. Energy Policy, Elsevier, v. 39, n. 2, p. 826-833, 2011.

TSCHAFFON, P. B.; MEZA, L. A. Assessing the efficiency of the electric energy distribution using data envelopment analysis with undesirable outputs. IEEE Latin America Transactions, IEEE, v. 12, n. 6, p. 1027-1035, 2014.

XAVIER, S. et al. How efficient are the brazilian electricity distribution companies? Journal of Control, Automation and Electrical Systems, Springer US, v. 26, n. 3, p. 283-296, 2015.

XUE, M.; HARKER, P. T. Note: Ranking dmus with infeasible super-efficiency dea models. Management Science, INFORMS, v. 48, n. 5, p. 705-710, 2002. 
ZANBOORI, E. et al. Calculating super efficiency of dmus for ranking units in data envelopment analysis based on sbm model. The Scientific World Journal, Hindawi Publishing Corporation, v. 2014, 2014. 